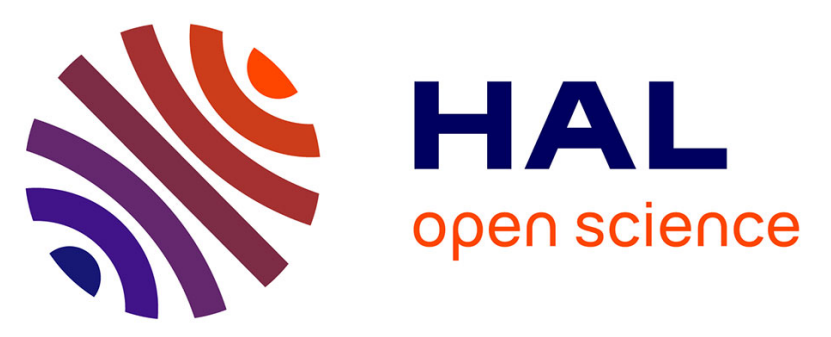

\title{
A role for the peroxisomal 3-ketoacyl-CoA thiolase B enzyme in the control of PPAR $\alpha$-mediated upregulation of SREBP-2 target genes in the liver.
}

Marco Fidaleo, Ségolène Arnauld, Marie-Claude Clémencet, Grégory Chevillard, Marie-Charlotte Royer, Melina de Bruycker, Ronald J. A. Wanders, Anne Athias, Joseph Gresti, Pierre Clouet, et al.

\section{To cite this version:}

Marco Fidaleo, Ségolène Arnauld, Marie-Claude Clémencet, Grégory Chevillard, Marie-Charlotte Royer, et al.. A role for the peroxisomal 3-ketoacyl-CoA thiolase B enzyme in the control of PPAR $\alpha$ mediated upregulation of SREBP-2 target genes in the liver.: ThB and cholesterol biosynthesis in the liver. Biochimie, 2011, 93 (5), pp.876-91. 10.1016/j.biochi.2011.02.001 . inserm-00573373

\section{HAL Id: inserm-00573373 https://www.hal.inserm.fr/inserm-00573373}

Submitted on 3 Mar 2011

HAL is a multi-disciplinary open access archive for the deposit and dissemination of scientific research documents, whether they are published or not. The documents may come from teaching and research institutions in France or abroad, or from public or private research centers.
L'archive ouverte pluridisciplinaire HAL, est destinée au dépôt et à la diffusion de documents scientifiques de niveau recherche, publiés ou non, émanant des établissements d'enseignement et de recherche français ou étrangers, des laboratoires publics ou privés. 
Fidaleo et al., ThB and genes of cholesterol biosynthesis in liver

3 Marco Fidaleo ${ }^{1,2,8 \#}$, Ségolène Arnauld ${ }^{1,2 \#}$, Marie-Claude Clémencet ${ }^{1,2}$, Grégory Chevillard ${ }^{1,2,9}$, 4 Marie-Charlotte Royer ${ }^{1,2}$, Melina De Bruycker ${ }^{3}$, Ronald J.A. Wanders ${ }^{4}$, Anne Athias ${ }^{5}$, Joseph 5 Gresti $^{1,6}$, Pierre Clouet ${ }^{1,6}$, Pascal Degrace ${ }^{1,6}$, Sander Kersten ${ }^{7}$, Marc Espeel ${ }^{3}$, Norbert Latruffe ${ }^{1,2}$, 6 Valérie Nicolas-Francès ${ }^{1,2}$ and Stéphane Mandard ${ }^{1,2, *}$

$7 \quad{ }^{1}$ Centre de recherche INSERM U866, Dijon, F-21000, France; ${ }^{2}$ Université de Bourgogne, Faculté des 8 Sciences Gabriel, Equipe Biochimie Métabolique et Nutritionnelle, Dijon, F-21000, France;

$9{ }^{3}$ Department of Human Anatomy, Embryology, Histology and Medical Physics, Ghent University,

10 Ghent, Belgium; ${ }^{4}$ Laboratory Genetic Metabolic Diseases, Academic Medical Center at the University

11 of Amsterdam, Meibergdreef 9, 1105 AZ Amsterdam, the Netherlands. ${ }^{5}$ Universite de Bourgogne,

12 IFR100, Plateau Technique de Lipidomique - Dijon, France. ${ }^{6}$ INSERM U866, Equipe

13 Physiopathologie des dyslipidémies, Faculté des Sciences Gabriel, 21000 Dijon, France; ${ }^{7}$ Nutrition,

14 Metabolism and Genomics group, Division of Human Nutrition, Wageningen University,

15 Wageningen, The Netherlands. ${ }^{8}$ Present address: Department of Cellular and Developmental Biology,

16 University of Rome "La Sapienza", P.le Aldo Moro 5, 00185 Rome, Italy. ${ }^{9}$ Present address: Lady

17 Davis Institute for Medical Research, McGill University, 3755 Côte Ste. Catherine Road, Montreal,
QC H3T 1E2, Canada;

*corresponding author: Stéphane MANDARD (PhD), LBMN, centre de recherche INSERM U866, 6, Boulevard Gabriel, 21000 Dijon, France. Phone: (+33) 3803962 02, Fax: (+33) 3803962 50, Email: stephane.mandard@u-bourgogne.fr

\# these authors contributed equally to this work.

Short title: ThB and cholesterol biosynthesis in the liver

Keywords: peroxisomal 3-ketoacyl-CoA thiolase B, PPAR $\alpha$, cholesterol, Wy14,643, Fatty Acid Oxidation. 
Fidaleo et al., ThB and genes of cholesterol biosynthesis in liver

\section{Abstract}

2 Peroxisomal 3-ketoacyl-CoA thiolase $B(T h b)$ catalyzes the final step in the peroxisomal $\beta$ -

3 oxidation of straight-chain acyl-CoAs and is under the transcription control of the nuclear hormone

4 receptor PPAR $\alpha$. PPAR $\alpha$ binds to and is activated by the synthetic compound Wy14,643 (Wy).

5 Here, we show that the magnitude of $\mathrm{Wy}$-mediated induction of peroxisomal $\beta$-oxidation of

6 radiolabeled $\left(1-{ }^{14} \mathrm{C}\right)$ palmitate was significantly reduced in mice deficient for Thb. In contrast,

7 mitochondrial $\beta$-oxidation was unaltered in $T h b^{-/-}$mice. Given that Wy-treatment induced Acox1

8 and MFP1/2 activity at a similar level in both genotypes, we concluded that the thiolase step alone

9 was responsible for the reduced peroxisomal $\beta$-oxidation of fatty acids. Electron microscopic

10 analysis and cytochemical localization of catalase indicated that peroxisome proliferation in the

11 liver after Wy-treatment was normal in $T h b^{-/-}$mice. Intriguingly, microarray analysis revealed that

12 mRNA levels of genes encoding for cholesterol biosynthesis enzymes were upregulated by Wy in

13 Wild-Type (WT) mice but not in $T h b^{-/-}$mice, which was confirmed at the protein level for the

14 selected genes. The non-induction of genes encoding for cholesterol biosynthesis enzymes by Wy

15 in $T h b^{-/-}$mice appeared to be unrelated to defective SREBP-2 or PPAR $\alpha$ signalling. No difference

16 was observed in the plasma lathosterol/cholesterol ratio (a marker for de novo cholesterol

17 biosynthesis) between Wy-treated WT and $T h b^{-/-}$mice, suggesting functional compensation.

18 Overall, we conclude that ThA and SCPx/SCP2 thiolases cannot fully compensate for the absence

19 of ThB. In addition, our data indicate that $\mathrm{ThB}$ is involved in the regulation of genes encoding for

20 cholesterol biosynthesis enzymes in the liver, suggesting that the peroxisome could be a promising

21 candidate for the correction of cholesterol imbalance in dyslipidemia. 
Fidaleo et al., ThB and genes of cholesterol biosynthesis in liver

\section{Introduction}

2 Over the last decade, considerable effort has been made to disentangle the various pathways in

3 which peroxisomes are involved. Evidence abounds that defects in peroxisome biogenesis and $\beta$ -

4 oxidation of fatty acids cause several inherited diseases, which - in most cases - are lethal [1].

5 Peroxisomes are known to be involved in many aspects of lipid metabolism, including synthesis of

6 bile acids and plasmalogens, synthesis of cholesterol and isoprenoids, $\alpha$-oxidation and $\beta$-oxidation

7 of very-long-straight- or -branched-chain acyl-CoAs. The peroxisomal degradation of straight-

8 chain acyl-CoAs by a discrete set of enzymes has been well documented. The $\beta$-oxidation of

9 straight-chain acyl-CoAs starts with a reaction catalyzed by acyl-CoA oxidase 1 (Acox1), the rate-

10 limiting enzyme of the $\beta$-oxidation pathway. This step is followed by two enzymatic reactions

11 carried out by the MFP1/L-bifunctional protein and the MFP2/D-bifunctional protein. The fourth

12 and last step is catalyzed by the peroxisomal 3-ketoacyl-CoA thiolases.

13 Intriguingly, two different peroxisomal 3-ketoacyl-CoA thiolases for very-long-straight-chain fatty

14 acids (thiolase A, ThA, Acaala and thiolase B, ThB, Acaalb, EC:2.3.1.16) have been cloned in

15 rodents, while only one corresponding gene (peroxisomal 3-acetyl-CoA acetyltransferase-1,

16 ACAA1) has been identified in humans [2-4]. The third peroxisomal thiolase, SCP-2/3-ketoacyl-

17 CoA thiolase (SCPx), displays a very broad substrate specificity, including cleavage of 2-methyl

18 branched as well as straight-chain 3-ketoacyl-CoA esters $[1,5,6]$.

19 Targeted disruption of the mouse Acoxl gene has revealed the critical role of this enzyme in

20 hepatocellular proliferation and peroxisome proliferation as well as in the catabolism of very-long-

21 chain fatty acids $[7,8]$. Peroxisomal acyl-CoA oxidase deficiency and its consequences are also

22 well documented in humans [9]. Two isoforms of ACOX1 (a and b) have been characterized in

23 mouse and man [10]. Vluggens et al. recently studied the respective roles of these isoforms by

24 using adenovirally driven hACOX-1a and hACOX-1b in Acoxl null mice [10, 11]. The hACOX-1b

25 isoform was more effective in reversing the Acoxl null phenotype than the hACOX-1a isoform,

26 illustrating functional differences between these two closely related proteins. Other reports aimed 
Fidaleo et al., ThB and genes of cholesterol biosynthesis in liver

1 at characterizing the consequences of $M f p-1$ (L-PBE) and/or $M f p-2$ (D-PBE) deficiencies in mice

2 are also available [12]. While most biochemical parameters remained unaffected by the single

3 deletion of $M f p-1, M f p-1$ deficient mice displayed marked reduction in peroxisome proliferation

4 when challenged with a peroxisome proliferator [13]. The $M f p-2$ deficient mice displayed

5 disturbances in bile acid metabolism and in the breakdown of very-long-chain fatty acids. Recently,

6 it was also reported that deletion of $M f p-2$ in mice resulted in the combined upregulation of

7 PPARalpha and SREBP-2 target genes in the liver, suggesting a potential cross-talk between the

8 two signalling cascades, orchestrated by MFP-2 [14].

9 Information about ACAA1 remains fragmentary and only a limited number of studies has been

10 reported so far $[4,15]$. The discovery of a young girl with a specific mutation within the $A C A A 1$

11 gene was initially believed to shed some light on the role of ACAA1 in very-long-chain fatty acid

12 catabolism [16]. However, follow-up investigations demonstrated that the true defect was rather at

13 the level of D-bifunctional protein, rendering the impact of ACAA1 in humans uncertain [15]. To

14 date, it is not clear if ACAA1 plays a similar role in humans and rodents, nor whether ACAA1 can

15 be considered as the ortholog of ThA and/or ThB [2]. Hence, in an effort to improve our

16 understanding of the functions of peroxisomal 3-ketoacyl-CoA thiolases, we began by studying the

17 deletion of $T h b$ in mice [17].

18 As a hypolipidemic fibrate drug, the synthetic peroxisome proliferator Wy14,643 (Wy) causes

19 proliferation of peroxisomes in liver parenchymal cells [18]. In WT mice, Wy administration gives

20 rise to a robust elevation of mitochondrial and peroxisomal fatty acid $\beta$-oxidation, hepatocyte

21 hyperplasia and then hepatomegaly, but these effects are not found in PPAR $\alpha$ deficient mice [19].

22 At the molecular level, Wy has been characterized as a potent and selective activator of the nuclear

23 hormone receptor PPAR $\alpha$ in humans and rodents [20, 21]. PPAR $\alpha$ is well expressed in

24 metabolically active tissues such as hepatic, renal and brown adipose tissue [22]. After binding of

$25 \mathrm{Wy}$, PPAR $\alpha$ becomes activated and regulates the expression of a subset of genes commonly

26 referred to as PPAR $\alpha$ target genes [23]. Previously, Thb was identified as a gene highly responsive 
Fidaleo et al., ThB and genes of cholesterol biosynthesis in liver

1 to PPAR $\alpha$ agonists $[24,25]$. Therefore Thb mRNA levels can be modulated by treatment with

2 peroxisome proliferators (PP). In addition to being crucial for lipid handling, PPAR $\alpha$ has been

3 linked to the regulation of genes involved in cell growth, differentiation and inflammation control

4 [26-29]. Using gene expression profiling combined with northern-blotting or RT-qPCR

5 experiments, it has also been established that the effects of $\mathrm{Wy}$ on hepatic gene expression are

6 robust and almost exclusively mediated by PPAR $\alpha[30,31]$.

7 Since $T h b$ expression is highly activated by PPAR $\alpha$, it can be hypothesized that the effect of $T h b$

8 deletion would be more pronounced under conditions of PPAR $\alpha$ activation. Accordingly, the effect

9 of $T h b$ deletion was studied in WT mice and $T h b^{-/}$mice, both treated with Wy for 8 days, and

10 fasted for $6 \mathrm{~h}$ before sacrifice. The results indicate that $T h B$ inactivation is associated with a modest

11 but statistically significant decrease in peroxisomal palmitate $\beta$-oxidation. It is also worth noting

12 that $\mathrm{ThB}$ is dispensable for $\mathrm{Wy}$-mediated cell and peroxisome proliferation in the liver.

13 Intriguingly, the Wy-induction of some genes encoding for cholesterol biosynthesis enzymes was

14 altered in $\mathrm{Thb}^{-/}$mice, suggesting that $\mathrm{ThB}$ has a unique and unexpected role in cholesterol

15 metabolism.

\section{2. Materials and methods}

\subsection{Animals}

20 Male, pure-bred Sv129 (WT) and $T h b^{-/}$mice have been previously described [17]. Mice were kept

21 in normal cages with food and water ad libitum, unless indicated. Mice were routinely fed a

22 standard commercial pellet diet (UAR A03-10 pellets from Usine d'Alimentation Rationnelle,

23 Epinay sur Orge, France, $3.2 \mathrm{kcal} / \mathrm{g}$ ) consisting (by mass) about 5.1\% fat (C16:0 0.89\% ; C16:1n-7 $24 \pm 0.09 \%$; $\mathrm{C} 18: 0 \pm 0.45 \%$; C18:1n-9 $\pm 1.06 \%, \mathrm{C} 18: 2 \mathrm{n}-9 \pm 1.53 \%$ and traces of $\mathrm{C} 18: 3 \mathrm{n}-9)$. At the

25 time of sacrifice, animals were around 4-5 months old. Unless indicated, male mice in the fasted

26 state were deprived of food for $6 \mathrm{~h}$ starting at 4:0 pm. Blood was collected via orbital puncture into

27 EDTA tubes. The animal experiments were approved by the animal experimentation committee of 
Fidaleo et al., ThB and genes of cholesterol biosynthesis in liver

1 the University of Burgundy (protocol number $\mathrm{n}^{\circ} 1904$ ) and were performed according to European

2 Union guidelines for animal care.

3

\subsection{Chemicals}

5 For the purposes of the present work, Wy was obtained from ChemSyn Laboratories (Lenexa,

6 Kansas), Fenofibrate from Sigma, Arabic gum from Merck, qPCR MasterMix Plus for SYBR

7 Green I with fluorescein from Eurogentec, and $\left(1-{ }^{14} \mathrm{C}\right)$ palmitate from Amersham Biosciences.

8

\subsection{Pharmacological protocol}

10 Male mice were treated by intragastric gavage with two kinds of peroxisome proliferators: (1) Wy

11 (30 mg/kg/day, approximately $200 \mu \mathrm{l} /$ dose) for 8 days, and (2) fenofibrate (100 mg/kg/day, 200

$12 \mu \mathrm{l} /$ day) for 14 days. In both cases, these molecules were dispersed into water containing $3 \%$ Arabic

13 gum. This protocol was performed daily between 8.00 a.m. and 10.00 a.m. Livers were excised,

14 weighed, snap-frozen in liquid nitrogen, and stored at $-80{ }^{\circ} \mathrm{C}$. For the RNA analyses, tissue

15 samples were taken from the same liver lobe in each mouse to avoid variability.

16

18 Peroxisomal and mitochondrial oxidation of $\left(1-{ }^{14} \mathrm{C}\right)$ palmitate were measured as described 19 elsewhere [32]. However, instead of quantifying the ${ }^{14} \mathrm{CO} 2$ radioactivity level, the release of (1-

$\left.20{ }^{14} \mathrm{C}\right)$ acetyl-CoA and $\left(1-{ }^{14} \mathrm{C}\right)$ acetyl-carnitine in perchloric acid was quantified after one cycle of $\beta$ 21 oxidation.

24 Liver homogenates and mitochondrial fractions were prepared as usually described [33]. Livers

25 were homogenized with a Teflon pestle rotating at $300 \mathrm{rpm}$ in a cooled Potter-Elvehjem

26 homogenizer, in 20 volumes of chilled solution of $0.25 \mathrm{M}$ sucrose, $2 \mathrm{mM}$ EGTA, and $10 \mathrm{mM}$ Tris-

$27 \mathrm{HCl}(\mathrm{pH}$ 7.4). Palmitate oxidation rates were measured in two separate media: the first allowed 
Fidaleo et al., ThB and genes of cholesterol biosynthesis in liver

1 both mitochondrial and peroxisomal activities to occur, and the second allowed only peroxisomal

2 activity. The functional state of mitochondria was estimated by the differential activities of

3 monoamine oxidase (EC 1.4.3.4) and of citrate synthase (EC 4.1.3.7), whereas that of peroxisomes

4 were determined by $\mathrm{CN}$-insensitive palmitoyl-CoA-dependent NAD+ reduction, which has been

5 defined as the "peroxisomal fatty acid oxidizing system" (PFAOS) [34-36]. Carnitine

6 palmitoyltransferase I alpha (CPT-I $\alpha)$ activity was measured using L- $\left({ }^{3} \mathrm{H}\right)$ carnitine $(92.5 \mathrm{GBq} / \mathrm{mol}$;

7 Amersham Biosciences TRK762) with palmitoyl-CoA, as described elsewhere [32].

8

\subsection{Cytochemical localization of catalase and peroxisome electron microscopy}

10 Peroxisomes were identified in liver sections at light and electron microscopy levels, thereby

11 revealing the enzymatic activity of catalase, the main peroxisomal marker enzyme, according to

12 established procedures [37, 38]. Liver samples were fixed in a $4 \%$ formaldehyde, $0.1 \mathrm{M}$

13 sodiumcacocylate buffer ( $\mathrm{pH} 7.3$ ) containing $1 \%(\mathrm{w} / \mathrm{v})$ calcium chloride for $24 \mathrm{~h}$ at room

14 temperature, after which sections $(60 \mu \mathrm{m})$ were cut with a cryostat. The cryostat sections were then

15 incubated in a diaminobenzidine (DAB)-hydrogenperoxide medium at $\mathrm{pH} 10.5$ (Theorell-

16 Stenhagen buffer) for 3 hours at $25^{\circ} \mathrm{C}$. After DAB-incubation, the sections were rinsed, post-

17 osmicated and embedded in epoxy resin (LX-112) following standard protocols. Semi-thin $(2 \mu \mathrm{m})$

18 sections were cut for light microscopy, and ultra-thin $(750 \mathrm{~nm})$ sections for electron microscopy.

\subsection{Histochemistry/Histology.}

21 We kindly acknowledge the expertise of Amandine Bataille (Plateau technique d'imagerie 22 cellulaire CellImaP, IFR 100 Santé-STIC, Dijon, France) for liver sections and staining with 23 hematoxylin and eosin.

\subsection{In vivo proliferation assay of liver cells}

26 After sacrifice of the animals, liver samples were taken from each treatment group. The samples

27 were placed in $4 \%$ formalin overnight, incubated in $70 \%$ ethanol and dehydrated through a graded 
Fidaleo et al., ThB and genes of cholesterol biosynthesis in liver

1 series of alcohol (80\%-100\%). Finally, liver samples were placed in xylene before being embedded

2 in paraffin. Paraffin sections $(4 \mu \mathrm{m}$ thick) were cut and fixed to polylysine-coated slides.

3 Proliferative activity was then measured by labeling of the Ki-67 antigen, which is expressed in the

4 nuclei of all cells in G1, S, G2, and M phases. After removing paraffin with xylene, sections were

5 re-hydrated in a graded series of ethanol from $100 \%$ to $95 \%$. Endogenous peroxidase was blocked

6 with $3^{\circ}{ }^{\circ} \mathrm{H} 2 \mathrm{O} 2$ in methanol for $10 \mathrm{~min}$. All sections were pre-treated in a microwave oven in a 10

$7 \mathrm{mM}$ citrate buffer at $\mathrm{pH}=6$ for 10 minutes at $100^{\circ} \mathrm{C}$. Non-specific binding sites were blocked

8 using $10 \%$ goat serum (diluted in PBS $0.1 \%$ and triton X-100) before an incubation of $2 \mathrm{~h}$ at room

9 temperature. Incubation with anti-Ki-67 (AB9260, Millipore), the primary polyclonal antibody,

10 was then performed, followed by incubation with a goat anti-rabbit IgG secondary antibody (Santa

11 Cruz Biotechnology, sc-2004). Ki-67 positive cells were visualized by exposing the peroxidase to

12 3,3'-diaminobenzidine hydrochloride chromogen substrate (DAKO, K3467, France) following by

13 counterstaining with hematoxylin. Slides were then washed with deionized water and mounted with

14 a permanent medium (Clearmount mounting solution, Invitrogen Ltd., cat. no. 00-8010). It is also

15 worth noting that all cells in the active phases of the cell cycle stained brown except G0-phase

16 cells, which remained blue. To determine mitotic activity, an average of 4 fields on each slide was

17 analysed per animal $(n=3)$. The Ki-67 labelling index was defined as Ki-67 positive cells/total cells

18 present in the field.

\subsection{Plasma metabolites}

21 Plasma was initially collected into EDTA tubes via retro-orbital punctures and then centrifuged at

$224^{\circ} \mathrm{C}(10 \mathrm{~min}, 6000 \mathrm{rpm})$. Plasma $\beta$-hydroxybutyrate levels were determined using a $\beta$ -

23 hydroxybutyrate-FS kit (Diasys Diagnostic Systems International, France). Plasma free fatty acid

24 levels were evaluated with the NEFA-C kit from WAKO.

25 For lathosterol measurements, plasma was mixed with epicoprostanol, which was used as a control

26 standard. Potassium hydroxide saponification was followed by lipid extraction with hexane.

27 Cholesterol and lathosterol were analyzed in the trimethylsilyl ether state by GC-MS using a 
Fidaleo et al., ThB and genes of cholesterol biosynthesis in liver

1 Hewlett Packard HP6890 Gas Chromatograph equipped with an HP7683 Injector and an HP5973

2 Mass Selective Detector.

3

\subsection{RNA isolation and reverse transcription step}

5 Liver RNA was extracted with a TRIzol reagent (Invitrogen) using the supplier's instructions. RNA

6 was then further purified (from free nucleotides and contaminating genomic DNA) using RNeasy

7 columns (Qiagen) and DNAse treatment. $1 \mu \mathrm{g}$ of RNA was used for reverse transcription with

8 iScript Reverse Transcriptase (Bio-rad).

\subsection{Oligonucleotide microarray}

11 Liver RNA samples, prepared using a TRIzol reagent, were collected from four groups of five

12 mice. One group of 5 WT mice and one group of $5 \mathrm{Thb}^{-/}$mice had been treated with Wy, the other

13 two groups (5 WT mice and $5 \mathrm{Thb}^{-/}$mice) had not been treated with Wy. An equivalent amount of

14 RNA from each animal (from all four groups) was subsequently pooled. Pooled RNA was further

15 purified using Qiagen RNeasy columns and the quality was verified using an Agilent bioanalyzer

162100 (Agilent technologies, Amsterdam, the Netherlands). RNA was judged suitable for array

17 hybridization if the sample showed intact bands corresponding to the $18 \mathrm{~S}$ and 28S rRNA subunits

18 and no chromosomal peaks. As in a previous study, $10 \mu \mathrm{g}$ of RNA was used for one cycle of cRNA

19 synthesis (Affymetrix, Santa Clara, USA) [39]. Hybridization, washing and scanning of Affymetrix

20 GeneChip mouse genome 4302.0 arrays were performed following standard Affymetrix protocols.

21 Fluorimetric data were processed by Affymetrix GeneChip Operating software, and the gene chips

22 were globally scaled to all probe sets with an identical target intensity value. Further analysis was

23 performed using Data Mining Tools (Affymetrix).

\subsection{Real-Time Quantitative PCR}

26 PCR reactions were performed using the qPCR MasterMix Plus for SYBR Green I with fluorescein

27 (Eurogentec). All PCR reactions were performed with MultiGuard Barrier Tips (Sorenson 
Fidaleo et al., ThB and genes of cholesterol biosynthesis in liver

1 BioScience, Inc.) and an iCycler PCR machine (Bio-Rad Laboratories). Primers were designed to

2 generate a PCR amplification product of 50-120 bp and were selected following the

3 recommendations provided with the Primer 3 software (http://frodo.wi.mit.edu/cgi-

4 bin/primer3/primer3_www.cgi). The specificity of the amplification was verified via melt curve

5 analysis, and the efficiency of PCR amplification was evaluated by a standard curve procedure. The

6 expression of each gene was determined relative to 36B4 as a control gene and the relative gene

7 expression was calculated by using the "delta-delta $\mathrm{Ct}$ " quantification method.

8

10 Nuclear extracts of liver were prepared following established protocols [40].

$1310 \mu \mathrm{g}$ of nuclear protein was separated on a $10 \%(\mathrm{w} / \mathrm{v})$ polyacrylamide gel in the presence of $0.1 \%$

$14(\mathrm{w} / \mathrm{v})$ SDS and transferred on to PVDF membranes. A broad range pre-stained SDS-PAGE 15 standard (Bio-Rad, 161-0318) was used as a protein ladder in this study. After membrane saturation 16 at room temperature for 90 minutes with TBS $(0.1 \mathrm{M}$ Tris- $\mathrm{HCl}, \mathrm{pH} 8.0,0.15 \mathrm{M} \mathrm{NaCl})$ containing $170.1 \%(\mathrm{v} / \mathrm{v})$ Tween 20 and 5\% (w/v) fat-free milk, blots were then incubated overnight at $4^{\circ} \mathrm{C}$ with a 18 polyclonal rabbit antibody against HMG-CoA reductase (sc-33827, 1:200, Santa Cruz

19 Biotechnology); a polyclonal anti-actin rabbit antibody (A2066, 1:5000, Sigma); a polyclonal anti-

20 SREBP-2 rabbit antibody (Ab28482, 1:200, Abcam); a polyclonal anti-PPAR $\alpha$ rabbit antibody (sc-

21 9000, Santa Cruz Biotechnology); a monoclonal mouse antibody against the TATA-binding protein

22 (Ab818,1:2000, Abcam); and a polyclonal sheep antibody to histone H1 (Ab1938, Abcam),

23 respectively. High affinity purified antibodies reacting against phosphomevalonate kinase (Pmvk,

24 1:500) and mevalonate kinase (Mvk, 1:1000) have been characterized elsewhere [41]. Similarly,

25 the polyclonal rabbit antibody reacting against both thiolase A and B proteins (PTL, 1:15000) and

26 the mouse antibody reacting against Acox1 (1:200) have also been previously characterized [41-

27 43]. After three washes in TBS containing $0.1 \%$ (v/v) Tween 20, primary antibodies were detected 
Fidaleo et al., ThB and genes of cholesterol biosynthesis in liver

1 using a peroxidase-conjugated IgG antibody, the choice of which depends on the primary antibody

2 of interest: a goat anti-rabbit IgG Antibody, (1:30000, sc-2004, Santa Cruz Biotechnology), a goat

3 anti-mouse IgG antibody, (1:30000, Sc-2005, Santa Cruz Biotechnology) or a rabbit anti-sheepIgG

4 antibody (Ab6747, Abcam). The protein bands labelled with the antibodies were visualized using a

5 Western-blotting chemiluminescence luminol reagent (Santa Cruz Biotechnology) by exposure to

6 X-ray films (Amersham). Densitometry of proteins on Western blots was performed using the

7 Scion Image software.

8

9

\subsection{Liver cholesterol}

11 About $100 \mathrm{mg}$ of each liver sample was saponified by heating in ethanol-KOH, and then

12 cholesterol was extracted from the saponified solution with hexane. Epicoprostanol (5 $\beta$-cholestan-

$133 \alpha$-ol) was used as a standard. After evaporation of hexane, cholesterol was converted to

14 trimethylesters using bis-silyl-trifluoracetamide. Hepatic total cholesterol was subsequently

15 quantified by gas chromatography. To measure cholesterol ester levels, Folch extraction was

16 followed by a silylation step using bis (trimethyl-silyl) trifluoro-acetamide. Free cholesterol

17 concentration was taken to be the difference between total and esterified cholesterol.

\subsection{Statistical analyses}

20 Data are presented as means with their standard errors. The effects of genotype (KO vs WT), of

21 treatment (with or without Wy), and of genotype-treatment interaction were evaluated using a two-

22 way ANOVA test. The cut-off for statistical significance was set at a p-value of 0.05 .

\section{4. Results}

\section{4.1. Peroxisomal palmitate oxidation is reduced in $\mathrm{Wy}$-treated $\mathrm{Thb}^{-/-}$mice}

26 As previously shown, we found that Thb expression was strongly induced by Wy (Fig. 1a).

27 Interestingly, Tha expression was higher in $T h b^{-/}$mice treated with $\mathrm{Wy}$ (Wy-genotype interaction, 
Fidaleo et al., ThB and genes of cholesterol biosynthesis in liver

$1 \mathrm{p}=0.046$ ), indicating a possible compensation of the non-expression of the thb gene (Fig. 1a). A

2 Western-blotting experiment performed with an antibody unable to distinguish between ThA and

3 ThB isotypes confirmed the hepatic enrichment of ThA in $T h b^{-/-}$mice treated with Wy (Fig. 1b).

4 When compared to WT mice, the Acox $1, M f p-1$ and $S c p x / S c p 2$ thiolase mRNA levels were clearly

5 higher in $T h b^{-/}$mice, and statistically significant at face value $(\mathrm{p}=0.0506 ; \mathrm{p}=0.017 ; \mathrm{p}=0.0506$ for

6 Acox $1, M f p-1$ and $S c p x / S c p 2$, respectively). After treatment with $\mathrm{Wy}$, the $M f p-1 m R N A$ level was

7 significantly higher in $T h b^{-/}$mice (Wy-genotype interaction, $\mathrm{p}=0.004$ ), while the $S c p x / S c p 2$

8 thiolase and Acoxl mRNA levels increased in a similar way (which was further confirmed at the

9 protein level for Acox1, Fig. 1d) (Fig. 1c, p=0.252). To determine whether lack of Thb in mice

10 translates into functional alteration of fatty acid $\beta$-oxidation, we measured the rate of peroxisomal

$11 \beta$-oxidation of $\left(1-{ }^{14} \mathrm{C}\right)$ palmitate, using a liver homogenate from each mouse, both WT and $T h b^{-/}$,

12 with and without Wy-treatment (Fig. 1f). The effect of Thb deletion on the peroxisomal $\beta$ -

13 oxidation of $\left(1-{ }^{14} \mathrm{C}\right)$ palmitate was Wy-sensitive (Wy-genotype interaction, $\mathrm{p}=0.0035$ ), indicating

14 that the deletion of $T h b$ leads to a significant decrease $(-31 \%)$ in the induction of $\beta$-oxidation. Thb

15 inactivation did not affect the production of NADH (which shows the enzymatic activity of Acox1

16 and MFP-1/MFP-2) regardless of the treatment conditions (Fig. 1g). It is therefore clear that ThA

17 and SCPx thiolases cannot fully compensate for ThB when $T h b^{-/-}$mice are metabolically

18 challenged by the increase in fatty acid oxidation that Wy induces.

\section{4.2. Lack of ThB does not affect mitochondrial palmitate oxidation}

21 Although $T h b$ deletion caused a reduced rate of peroxisomal palmitate $\beta$-oxidation, it had no effect

22 on mitochondrial palmitate oxidation in Wy-treated $T h b^{-/}$mice, as shown by the results for the

23 liver homogenate (Fig. 2a), and for the liver mitochondrial fraction (Fig. 2b). Consistent with these

24 data, mRNA levels, the activities of Carnitine Palmitoyl Transferase-I $\alpha$ (CPT-I $\alpha)$ and of the two

25 mitochondrial markers, MonoAmine Oxidase (MAO) and Citrate Synthase (CS) were similar for 
Fidaleo et al., ThB and genes of cholesterol biosynthesis in liver

1 WT mice and $T h b^{-/-}$mice (Table 1 and supplemental Table 1). Additionally, circulating free fatty

2 acids (FFA) and $\beta$-hydroxybutyrate levels were not significantly altered in $T h b^{-/}$mice, both with

3 and without Wy-treatment, or after 24 h-fasting (Table 1). Taken together, the data show that Thb

4 deletion has very little impact on mitochondrial fatty acid $\beta$-oxidation, but that it has a negative

5 effect on peroxisomal fatty acid $\beta$-oxidation when mice are metabolically challenged.

6

\section{4.3. Wy-treated $T h b^{-/-}$mice display hepatomegaly similar to WT mice}

8 Besides alteration of lipid metabolism, the knockout of the Acoxl gene in mice is widely

9 acknowledged to be associated with major hepatomegaly combined with the absence of

10 peroxisomes [7]. In order to check for the possible impact of $T h b$ deletion on hepatomegaly, the

11 relative liver mass was evaluated for both genotypes. The hepatosomatic index was significantly

12 lower in $T h b^{-/}$mice than in WT mice $(\mathrm{p}=0.0136)$ (Fig. 3a). After Wy-treatment, the hepatosomatic

13 index increased in mice of both genotypes, although less in $T h b^{-/-}$mice, suggesting the possible

14 involvement of ThB in Wy-induced hepatomegaly (Wy-genotype interaction, $\mathrm{p}=0.004$ ). To further

15 investigate the putative role of ThB in hepatocyte proliferation, the size and number of liver cells

16 were quantified by histological staining using hematoxylin and eosin. Both parameters were

17 affected by Wy: cell numbers decreased and cell surface increased. No genotype effect per se was

18 observed either for cell number $(\mathrm{p}=0.105)$ or cell surface $(\mathrm{p}=0.250)$ (Fig.3b), suggesting that Thb

19 deletion has no marked effect on liver cell morphology (Fig. 3c). To assess the possible

20 implication of ThB in liver cell proliferation, Ki-67 immunohistochemistry was evaluated. Ki-67, a

21 nuclear protein preferentially expressed during all active phases of the cell cycle (G1, S1 and G2)

22 and mitosis, is absent in quiescent cells. The number of Ki-67 positive cells was low for both WT

23 and $T h b^{--}$hepatocytes (Fig.3d). Consistent with the results from the macroscopic observations, the

24 labelling index from the 8-day exposure of mice to Wy showed a similar increase for both WT and

$25 T h b^{-/}$hepatocytes (Fig. 3d) indicating that ThB was probably dispensable for cell proliferation in

26 liver. 
Fidaleo et al., ThB and genes of cholesterol biosynthesis in liver

\section{4.4. $\boldsymbol{T h}^{-/-}$mice display regular peroxisome biogenesis and proliferation in liver}

3 To assess for possible defects in peroxisomal assembly in $T h b^{-/-}$mice, we performed microscopic

4 studies of liver sections. At light microscopy level, these studies revealed a distinct pattern of

5 numerous, DAB-reactive granules in the hepatocyte cytoplasm of WT mice, with normal

6 peroxisome distribution (Fig. 4a). Similar peroxisome numbers and distribution were observed in

$7 \mathrm{Thb}^{-/}$hepatocytes, suggesting that ThB was dispensable for peroxisome biogenesis and

8 proliferation in normal conditions (Fig. 4c). These results are coherent with similar gene expression

9 of critical peroxins (such as Pex3p, Pex13p and Pex 16p) in both WT and $T h b^{-/}$mice, indicating

10 that $\mathrm{ThB}$ is dispensable for peroxisome biogenesis (supplemental Table 1). Wy-treatment caused

11 massive peroxisome proliferation in both WT and $T h b^{-/-}$hepatocytes (Fig. 4b, 4d). This result is

12 consistent with the increased mRNA levels of the PPAR $\alpha$ target gene Pexl $1 \alpha$ observed in both WT

13 and $T h b^{-/-}$mice (Fig. 4e). Taken together, these data indicate that ThB is dispensable for hepatic

14 peroxisome proliferation induced by $\mathrm{Wy}$.

15 Electron microscopy (EM) examination revealed that the liver peroxisomes were more elongated

16 and slightly more numerous in $T h b^{-/-}$mice than in WT mice (Fig. 4f, 4h). These data suggest that

17 Thb deletion does not cause the massive spontaneous peroxisome proliferation that has been

18 observed in the livers of mice deficient for Acoxl [8]. As expected, after Wy-treatment,

19 pronounced peroxisome proliferation was observed in both WT mice and $T h b^{-/}$mice.

23 4.5. Thb deletion blunts Wy-mediated upregulation of genes encoding for cholesterol 24 biosynthesis enzymes 
Fidaleo et al., ThB and genes of cholesterol biosynthesis in liver

1 In order to ascertain whether some metabolic steps are affected by Thb deletion, detailed analysis

2 of the microarray data was performed. In agreement with published data, Wy increased the

3 expression of several genes involved in de novo cholesterol biosynthesis (Fig. 5 and supplemental

4 Table 1) [44, 45]. However, this effect was significantly blunted in $T h b^{-/-}$mice, as shown by RT-

5 qPCR (Fig. 6). Similar data were collected for fenofibrate (Fig. 7). These data suggest that ThB

6 may be involved in hepatic cholesterol homeostasis via indirect regulation of the expression of

7 genes encoding for cholesterol biosynthesis enzymes.

9 4.6. Reduced content of cholesterol biosynthesis enzymes in the liver of Wy-treated $\mathrm{Thb}^{-/-}$

\section{0 mice is not secondary to reduced maturation of SREBP-2.}

11 Since the rate-controlling step in cholesterol biosynthesis is catalyzed by HMG-CoA reductase, we

12 checked whether the induction of Hmg-CoA reductase mRNA by Wy was translated at the protein

13 level. In coherence with the mRNA data, Wy increased HMG-CoA reductase protein content in

14 WT mice, but not in $T h b^{-/-}$mice (Fig. 8a). A similar pattern was observed for two enzymes found in

15 peroxisomes, phosphomevalonate kinase (Pmvk) and mevalonate kinase (Mvk), (Fig. 8a).

16 However, the pmvk mRNA levels did not reflect the increase in Pmvk at the enzyme level.

17 Therefore, we cannot completely rule out some post-translational modifications by intermediates of

18 the cholesterol and nonsterol isoprene biosynthetic pathways, as previously shown for Mvk [46]. In

19 coherence with an intact PPAR $\alpha$ signalling cascade in $T h b^{-/-}$mice, the nuclear PPAR $\alpha$ content was

20 not affected by Thb deletion or by the Wy-treatment (Fig. 8b).

21 Since genes encoding for cholesterol biosynthesis enzymes are under the direct control of the

22 transcription factor SREBP-2, the Srebp-2 mRNA level was quantified in liver samples of fibrate-

23 treated or mock-treated WT and $T h b^{-/-}$mice. No significant effects of Wy $(\mathrm{p}=0.792)$, fenofibrate

$24(\mathrm{p}=0.083)$ or $T h b$ deletion $(\mathrm{p}=0.71)$ on hepatic Srebp-2 mRNA were observed (Fig. 8c). Whatever

25 the genotype and pharmacological activation, the mature nuclear form of SREBP-2 remained

26 constant (Fig. 8c). These data suggest that the decrease in induction of cholesterol synthesis gene 
Fidaleo et al., ThB and genes of cholesterol biosynthesis in liver

1 expression in fibrate-treated $T h b^{-/-}$mice is probably not the consequence of defects in the

2 maturation process of SREBP-2.

3

4 4.7. The rate of in vivo cholesterol synthesis is reduced by Wy-treatment in both WT mice and

$5 \mathrm{Thb}^{-/-}$mice.

6 To investigate if the impact of Thb deletion on cholesterol synthesizing genes expression in the liver

7 results in an altered rate of cholesterol synthesis, the plasma lathosterol ( $5 \alpha$-cholest- 7 -en- $3 \beta$-ol) to

8 cholesterol ratio was determined. This ratio correlates well with the cholesterol balance and has

9 been used as an index of cholesterol biosynthesis [47, 48]. As reported in the literature, the

10 lathosterol/cholesterol ratio measured in the liver and in plasma was significantly reduced by Wy-

11 treatment $(\mathrm{Wy} ; \mathrm{p}=0.007)$ and fenofibrate-treatment $(\mathrm{FF} ; \mathrm{p}=0.042)$ in $\mathrm{WT}$ mice and in $T h b^{-/-}$mice

12 (Fig. 9a and 9c). In the liver, however, the steady-state hepatic cholesterol (total and free) content

13 remained stable after Wy-treatment in both WT mice and $T h b^{-/-}$mice, suggesting potential

14 compensatory mechanisms such as a decrease in catabolism of cholesterol to bile acids and/or a

15 decrease in its excretion in the stool (Fig. 9b and 9d).

\section{5. Discussion}

18 We recently reported on the hepatic enrichment of (n-7) and (n-9) mono-unsaturated fatty acids

19 (MUFAs) in the livers of $\mathrm{Wy}$-treated $T h b^{-/-}$mice [49]. Here, using radiolabelled $\left(1-^{14} \mathrm{C}\right)$ palmitate,

20 we show that peroxisomal fatty acid oxidation is not impaired by Thb deletion in the livers of

21 mock-treated mice. This new finding suggests that ThA and/or SCPx/SCP2 thiolase could replace

$22 \mathrm{ThB}$ in the absence of pharmacological stress.

24 After Wy-treatment, there was weaker induction of peroxisomal fatty acid oxidation in $T h b^{-/-}$mice,

25 indicating that ThA and/or SCPx/SCP2 thiolase cannot fully compensate for the lack of ThB under

26 conditions of metabolic stress. The role of ThB in the liver becomes crucial for peroxisomal fatty 
Fidaleo et al., ThB and genes of cholesterol biosynthesis in liver

1 acid oxidation when this function is activated. Even though ThA and ThB share almost complete

2 amino acid similarity (96\% identity), they do not necessarily share the same natural substrates and

3 their relative affinity for their substrates could be different [2].

4 It has previously been reported that the livers of Pex2- or Pex5-deficient mice are devoid of

5 functional peroxisomes [50, 51]. Elsewhere, fibroblasts derived from patients with ACOX1 or

6 MFP2 deficiency have been shown to exhibit a fivefold reduction in peroxisome abundance [52].

7 However, in some peroxisomal-disorder patients, peroxisome abundance was normal but their form

8 was elongated $[53,54]$. Here, we report that $T h b^{--}$mice have slightly elongated peroxisomes, but

9 the mechanism underlying this potentially interesting phenotype remains to be investigated.

10 Mice deficient for peroxisomal oxidative enzymes have fewer peroxisomes, supporting the

11 hypothesis that peroxisomal $\beta$-oxidation could partly control peroxisome abundance. Given that

12 reduced peroxisomal $\beta$-oxidation was observed in $\mathrm{Wy}$-treated $T h b^{-/-}$mice, we investigated the

13 function of $\mathrm{ThB}$ in this cellular process. Peroxisome abundance was shown to be related to the

14 presence or absence of Wy-treatment and not to genotype. Wy-treated $T h b^{-/-}$and WT mice both

15 had more peroxisomes than the mock-treated mice, indicating that the role of $\mathrm{ThB}$ in peroxisome

16 proliferation is minimal. Pex7-deficient mice have a disrupted peroxisomal receptor for ThB

17 import, but they nevertheless display normal peroxisome assembly, which confirms that

18 peroxisomal $\mathrm{ThB}$ is dispensable for peroxisome biogenesis [55]. One possible hypothesis is that

19 ThA and/or SCPX/SCP2 could compensate for the absence of ThB. However, similar Scpx/Scp2

20 mRNA levels were found in $\mathrm{WT}$ and $T h b^{-/-}$mice, making the SCPX/SCP2 hypothesis unlikely.

21 Furthermore, SCPX/SCP2-deficient mice had more peroxisomes in their livers, indicating that

$22 \mathrm{SCPX} / \mathrm{SCP} 2$ could impede peroxisome proliferation [6]. Elevated Tha mRNA levels in Wy-treated

$23 \mathrm{Thb}^{-/}$mice could reflect a response to the previously reported hepatic overload of (n-7) and (n-9)

24 MUFAs (Fig. 1) [49]. As the substrates and properties of ThA and ThB have still not been

25 completely explored, it is impossible to rule out a mechanism where ThA compensates for the

26 absence of $\mathrm{ThB}$, similar to the compensation observed between MFP-1 and MFP-2 in mice 
Fidaleo et al., ThB and genes of cholesterol biosynthesis in liver

1 deficient for these genes [56], (and reviewed in Ref. [5]), [57]. Thus, the generation of $T h a^{-/-}$mice

2 would be a positive step in exploring the role of ThA in peroxisome biogenesis, proliferation and

3 function. It could also help to clarify the respective contribution of ThA and $\mathrm{ThB}$ to various

4 substrates [56].

5 In contrast to $P e x 5^{--}$mice, which show a twofold increase in mitochondrial palmitate $\beta$-oxidation,

6 mitochondrial palmitate $\beta$-oxidation remains unchanged in $T h b^{-/-}$mice [58]. Furthermore, since

7 Thb deletion appears to have no effect on the structure of the mitochondria as revealed by electron

8 microscopy and on the activity of mitochondrial marker enzymes, we conclude that the biology of

9 the mitochondrion is not dependent on ThB.

10 Previous studies have described an incomplete cholesterol biosynthesis pathway in peroxisomes,

11 with conversion of the peroxisomal acetyl-CoA pool to HMG-CoA. The peroxisomal acetyl-CoA

12 pool produced by $\beta$-oxidation represents less than $10 \%$ of the total acetyl-CoA in the liver [59] and

13 is channelled preferentially to cholesterol biosynthesis [60-63]. Cholesterol biosynthesis followed

14 the same pattern in both $T h b^{-/}$and WT mice. As the total and free cholesterol content in the liver

15 was also similar in both $T h b^{-/}$and WT mice, ThB probably has a limited functional role in this

16 pathway, but compensation by ThA and/or SCPX/SCP2 cannot be ruled out.

17 It is worth recalling that our expression data are in coherence with the existing literature, showing

18 the induction of some genes encoding for cholesterol biosynthesis enzymes after Wy-treatment in

19 the livers of WT mice, but intriguingly not in those of $T h b^{-/}$mice $[44,45]$. However, the increase

20 in most mRNAs and proteins encoding for cholesterol biosynthesis after Wy-treatment in WT mice

21 was not accompanied by an increase in de novo cholesterol biosynthesis, as shown by the plasma

22 lathosterol/cholesterol ratio, a surrogate plasma marker for endogenous cholesterol biosynthesis

23 downstream from lanosterol [47]. These data are in line with various studies showing that fibrate-

24 treatment in WT mice does not stimulate hepatic production of cholesterol but rather decreases it

25 [45]. Given that well-established PPAR $\alpha$ target genes are equally upregulated in Wy-treated WT

26 and $T h b^{-/}$mice, why is it that SREBP-2 target genes (genes encoding for cholesterol biosynthesis 
Fidaleo et al., ThB and genes of cholesterol biosynthesis in liver

1 enzymes) do not follow the same pattern in Wy-treated WT and Thb ${ }^{-/}$mice [49]? Recent studies

2 have reported cross-talk between PPAR $\alpha$ and SREBP-2 dependent gene-regulation in human

3 hepatoma HepG2 cells, suggesting potential synergy between the PPAR $\alpha$ and SREBP-2 pathways

4 in humans $[64,65]$. It is possible that the SREBP-2 and perhaps even the SREBP-1 signalling

5 cascades may be compromised in Wy-treated $T h b^{-/-}$mice. However, many animal and cellular

6 studies exploring the level of expression of SREBP-2 and SREBP-1 have shown that, while

7 SREBP-2 is a relatively selective activator of cholesterol biosynthesis, SREBP-1 controls fatty acid

8 biosynthesis (reviewed in Refs. [66-68]). The mRNAs for several cholesterol biosynthesis enzymes

9 have been found to increase in transgenic mice expressing a dominant positive NH2-terminal

10 fragment of SREBP-la [69]. One possible hypothesis is that a decrease in SREBP-1 could cause a

11 decrease in the Wy-induction of genes encoding for cholesterol biosynthesis enzymes in $T h b^{-/-}$

12 mice. However, we consider this explanation very unlikely, as the maturation of SREBP-2 and

13 SREBP-1 is unaltered in $T h b^{-/-}$mice (this manuscript and Ref. [49]). In further support of this

14 notion, the mRNA levels of the lipogenic genes Acc $\alpha$ and Fas, two SREBP-1 targets, were more

15 elevated in Wy-treated $T h b^{-/-}$mice than in Wy-treated WT mice, suggesting that the SREBP-1

16 pathway was not compromised [49]. No difference in the mRNA level or the mature active form of

17 the protein was observed for SREBP-2 in WT and $T h b^{-/-}$mice, with or without Wy-treatment. The

18 activity of nuclear SREBP-2 is regulated by post-translational modifications [70]. For example,

19 insulin-like growth factor 1 (IGF-1) induces phosphorylation of SREBP-2, facilitating SREBP-2

20 transcriptional activity and thereby the expression of its target genes [70]. Thb ${ }^{-/}$mice are smaller

21 than WT mice and display a drastic reduction in liver $I g f-1$ mRNA and circulating levels

22 (unpublished data). A plausible hypothesis that should not be dismissed is that reduced IGF-1-

23 mediated phosphorylation of SREBP-2 could ultimately lead to reduced transcriptional activity of

24 SREBP-2 in Wy-treated $T h b^{-/}$mice. 
Fidaleo et al., ThB and genes of cholesterol biosynthesis in liver

1 Almost all the biological effects of Wy on gene expression have been shown to be mediated by the

2 nuclear receptor PPAR $\alpha$ [31]. The Wy-induction of genes encoding for cholesterol biosynthesis

3 enzymes has been shown to be dependent on PPAR $\alpha[44,45,71]$. Based on these statements, we

4 may speculate that the PPAR $\alpha$ signalling cascade may be altered by Thb deletion, explaining at

5 least in part the non-induction of genes encoding for cholesterol biosynthesis enzymes in Wy-

6 treated $T h b^{-/}$mice. However, the magnitude of $\mathrm{Wy}$ - or fibrate-induction in almost all typical

7 hepatic PPAR $\alpha$ target genes appears to remain at least the same in $T h b^{-/-}$mice, arguing against this

8 possibility (Fig. 1d and supplemental Fig. 2a and 2b) [49]. Significantly, van der Meer et al found

9 PPAR $\alpha$ binding to the human promoter of the SREBP target genes Hmgcs1, Hmgcr, Fdft1 and

10 Sc4mol, confirming cross-talk between PPAR $\alpha$ and SREBP [64]. In further support of this idea,

11 Leuenberger et al also reported the physical binding of PPAR $\alpha$ to the promoter of the Hmgcsl,

12 Hmgcr, Mvk and Pmvk genes in Wy-treated mice [65]. Together, these results indicate that

13 activated PPAR $\alpha$ could perhaps directly but unexpectedly control hepatic cholesterol biosynthesis.

14 In order to link PPAR $\alpha$ unequivocally to the impaired Wy-induction of genes encoding for

15 cholesterol biosynthesis enzymes, it would be necessary to establish $\operatorname{Ppar}^{-/} \times \mathrm{Thb}^{-/}$mice.

16 Another key nuclear receptor for cholesterol biosynthesis is the oxysterol receptor Liver $\mathrm{X}$

17 Receptor $\alpha(\operatorname{LXR} \alpha)$, which is regulated at the transcriptional level by PPAR $\alpha$ [72, 73]. By

18 silencing the expression of the two genes Cyp51 and Fdft1 encoding key cholesterologenic

19 enzymes via a negative DNA response element, LXR $\alpha$ counteracts the effects of SREBP-2.

20 However, LXR $\alpha$ is probably not involved in the impaired Wy-induction of Cyp51 and Fdft 1 genes

21 in $T h b^{-/-}$mice because the expression of $\operatorname{Lx} \alpha$ and its target genes was unaltered in Wy-treated Thb

$22^{\prime-}$ mice (data not shown and [49]).

23 In our previous comparative analysis of liver and plasma fatty acid composition, we found a

24 reduction in DHA (Docosahexaenoic acid, C22:6(n-3), a potent natural activator of PPAR $\alpha$ in vivo)

25 in Wy-treated $T h b^{-/}$mice, [31, 49]. There was also a reduction in hepatic arachidonic acid 
Fidaleo et al., ThB and genes of cholesterol biosynthesis in liver

1 (C20:4(n-6)), a natural agonist for the Retinoid X Receptor, in Wy-treated $T h b^{-/}$mice [49, 74].

2 Furthermore, recent data have also indicated that C16:1(n-7) decreases activation of the PPAR $\alpha$

3 target gene in the liver [75]. The amount of C16:1(n-7) is significantly increased in the livers of

4 Wy-treated $T h b^{-/}$mice. Changes in the availability of this metabolite in $T h b^{-/-}$mice may therefore

5 decrease the Wy-induction of cholesterologenic genes by selectively modulating receptor-

6 coregulator interactions.

7 Finally, it should be emphasized that Wy-treated $T h b^{-/-}$mice displayed enrichment of some (n-7)

8 and (n-9) MUFAs in the liver, as the probable consequence of higher Stearoyl-CoA Desaturase-1

9 (SCD1) activity [49]. Recent findings indicate that changes in the hepatic fatty acid composition of

10 the products of SCD1 modulate free cholesterol biosynthesis through a mechanism that implies

11 endoplasmic reticulum (ER) stress [76, 77]. While we cannot completely rule out a role for ER

12 stress in the dysregulation of SREBP-2 target genes by Wy in $T h b^{-/-}$mice, this explanation appears

13 very unlikely because deleting the $T h b$ gene in mice did not affect the expression pattern of the

14 main genes involved in the emergence of ER stress, as revealed by DNA arrays (data not shown).

15 To conclude, our data suggest that ThB plays a minor role in peroxisome biogenesis and

16 proliferation in the liver. The present work also suggests that under certain conditions of metabolic

17 stress, ThB may contribute to the indirect regulation by activated PPAR $\alpha$ of SREBP-2 target gene

18 expression. Like other studies on MFP-2 and Pex2p, our data strengthen the notion that defects in

19 peroxisomal enzymes impact on the mRNA levels of genes encoding for cholesterol biosynthesis

20 enzymes in the liver $[14,78]$. There may possibly be molecular and biochemical mechanisms to

21 explain our observations and these avenues should therefore be explored by direct experimentation

22 in the future. 
Fidaleo et al., ThB and genes of cholesterol biosynthesis in liver

1 Acknowledgments: This work was supported by grants from the European Union project "Peroxisomes" LSHG-CT-2004-512018, the Regional Council of Burgundy and the INSERM

3 U866 center (Dijon). G.C. was supported by a French Ministry of Research and Technology Ph.D.

4 fellowship and M.F. by the Italian "Ministero della Ricerca Scientifica e Tecnologica".

5 We thank staff members from the Centre de Zootechnie (Dijon, France) for their help in mice

6 housing and breeding, Jacques Kaminski for laboratory analyses and Dr Wim Kulik (Academic

7 Medical Center, University of Amsterdam) for carrying out the measurement of mevalonate in liver

8 homogenate samples. We are grateful to Amandine Bataille (Plateau technique d'imagerie

9 cellulaire CellImaP, IFR 100 Santé-STIC, Dijon) for her expertise in performing histological

10 studies. We are also indebted to Mechteld Grootte-Bromhaar for performing the micro-array

11 experiment and to Drs. Philip J. de Groot and Guido J.E.J. Hooiveld for their valuable contribution

12 to the analysis of the micro-array data. The authors are also indebted to Ms Carmela Chateau-Smith

13 for reviewing the English version of the manuscript.

15 Abbreviations: ThB: peroxisomal 3-ketoacyl-CoA thiolase B; ThA: peroxisomal 3-ketoacyl-CoA 16 thiolase A; ACOX1 (for human protein) or Acox1 (for mouse protein): peroxisomal acyl-CoA 17 oxidase-I; CPT-1 $\alpha$ : carnitine palmitoyltransferase-1alpha; DAB: DiAminoBenzidine; PPAR $\alpha$ : 18 Peroxisome Proliferator-Activated Receptor alpha; LCFAs: Long-Chain Fatty Acids; VLCFAs: 19 Very-Long-Chain Fatty Acids; MUFAs: Mono-Unsaturated Fatty Acids; Wy: Wy14,643; FF: 20 Fenofibrate.

\section{References}

[1] R.J. Wanders, S. Ferdinandusse, P. Brites, S. Kemp, Peroxisomes, lipid metabolism and lipotoxicity, Biochim. Biophys. Acta 1801 (2010) 272-280.

[2] G. Chevillard, M.C. Clemencet, P. Etienne, P. Martin, T. Pineau, N. Latruffe, V. Nicolas-Frances, Molecular cloning, gene structure and expression profile of two mouse peroxisomal 3-ketoacyl-CoA thiolase genes, BMC Biochem. 5 (2004) 3.

[3] M. Hijikata, J.K. Wen, T. Osumi, T. Hashimoto, Rat peroxisomal 3-ketoacyl-CoA thiolase gene. Occurrence of two closely related but differentially regulated genes, J. Biol. Chem. 265 (1990) 4600-4606.

[4] A. Bout, M.M. Franse, J. Collins, L. Blonden, J.M. Tager, R. Benne, Characterization of the gene encoding human peroxisomal 3-oxoacyl-CoA thiolase (ACAA). No large DNA rearrangement in a thiolase-deficient patient, Biochim. Biophys. Acta 1090 (1991) 43-51. 
Fidaleo et al., ThB and genes of cholesterol biosynthesis in liver

[5] Y. Poirier, V.D. Antonenkov, T. Glumoff, J.K. Hiltunen, Peroxisomal beta-oxidation--a metabolic pathway with multiple functions, Biochim Biophys Acta 1763 (2006) 1413-1426.

[6] U. Seedorf, M. Raabe, P. Ellinghaus, F. Kannenberg, M. Fobker, T. Engel, S. Denis, F. Wouters, K.W. Wirtz, R.J. Wanders, N. Maeda, G. Assmann, Defective peroxisomal catabolism of branched fatty acyl coenzyme A in mice lacking the sterol carrier protein-2/sterol carrier protein-x gene function, Genes Dev. 12 (1998) 1189-1201.

[7] C.Y. Fan, J. Pan, R. Chu, D. Lee, K.D. Kluckman, N. Usuda, I. Singh, A.V. Yeldandi, M.S. Rao, N. Maeda, J.K. Reddy, Hepatocellular and hepatic peroxisomal alterations in mice with a disrupted peroxisomal fatty acyl-coenzyme A oxidase gene, J. Biol. Chem. 271 (1996) 24698-24710.

[8] C.Y. Fan, J. Pan, N. Usuda, A.V. Yeldandi, M.S. Rao, J.K. Reddy, Steatohepatitis, spontaneous peroxisome proliferation and liver tumors in mice lacking peroxisomal fatty acylCoA oxidase. Implications for peroxisome proliferator-activated receptor alpha natural ligand metabolism, J. Biol. Chem. 273 (1998) 15639-15645.

[9] S. Ferdinandusse, S. Denis, E.M. Hogenhout, J. Koster, C.W. van Roermund, I.J. L, A.B. Moser, R.J. Wanders, H.R. Waterham, Clinical, biochemical, and mutational spectrum of peroxisomal acyl-coenzyme A oxidase deficiency, Hum. Mutat. 28 (2007) 904-912.

[10] D. Oaxaca-Castillo, P. Andreoletti, A. Vluggens, S. Yu, P.P. van Veldhoven, J.K. Reddy, M. Cherkaoui-Malki, Biochemical characterization of two functional human liver acylCoA oxidase isoforms 1a and $1 \mathrm{~b}$ encoded by a single gene, Biochem. Biophys. Res. Commun. 360 (2007) 314-319.

[11] A. Vluggens, P. Andreoletti, N. Viswakarma, Y. Jia, K. Matsumoto, W. Kulik, M. Khan, J. Huang, D. Guo, S. Yu, J. Sarkar, I. Singh, M.S. Rao, R.J. Wanders, J.K. Reddy, M. Cherkaoui-Malki, Functional significance of the two ACOX1 isoforms and their crosstalks with PPARalpha and RXRalpha, Lab. Invest. 90 696-708.

[12] M. Baes, S. Huyghe, P. Carmeliet, P.E. Declercq, D. Collen, G.P. Mannaerts, P.P. Van Veldhoven, Inactivation of the peroxisomal multifunctional protein-2 in mice impedes the degradation of not only 2-methyl-branched fatty acids and bile acid intermediates but also of very long chain fatty acids, J. Biol. Chem. 275 (2000) 16329-16336.

[13] C. Qi, Y. Zhu, J. Pan, N. Usuda, N. Maeda, A.V. Yeldandi, M.S. Rao, T. Hashimoto, J.K. Reddy, Absence of spontaneous peroxisome proliferation in enoyl-CoA Hydratase/L-3hydroxyacyl-CoA dehydrogenase-deficient mouse liver. Further support for the role of fatty acyl CoA oxidase in PPARalpha ligand metabolism, J. Biol. Chem. 274 (1999) 15775-15780. [14] K. Martens, E. Ver Loren van Themaat, M.F. van Batenburg, M. Heinaniemi, S. Huyghe, P. Van Hummelen, C. Carlberg, P.P. Van Veldhoven, A. Van Kampen, M. Baes, Coordinate induction of PPARalpha and SREBP2 in multifunctional protein 2 deficient mice, Biochim. Biophys. Acta (2008).

[15] S. Ferdinandusse, E.G. van Grunsven, W. Oostheim, S. Denis, E.M. Hogenhout, I.J. L, C.W. van Roermund, H.R. Waterham, S. Goldfischer, R.J. Wanders, Reinvestigation of peroxisomal 3-ketoacyl-CoA thiolase deficiency: identification of the true defect at the level of d-bifunctional protein, Am. J. Hum. Genet. 70 (2002) 1589-1593.

[16] A.W. Schram, S. Goldfischer, C.W. van Roermund, E.M. Brouwer-Kelder, J. Collins, T. Hashimoto, H.S. Heymans, H. van den Bosch, R.B. Schutgens, J.M. Tager, et al., Human peroxisomal 3-oxoacyl-coenzyme A thiolase deficiency, Proc. Natl. Acad. Sci. U S A 84 (1987) 2494-2496.

[17] G. Chevillard, M.C. Clemencet, N. Latruffe, V. Nicolas-Frances, Targeted disruption of the peroxisomal thiolase B gene in mouse: a new model to study disorders related to peroxisomal lipid metabolism, Biochimie 86 (2004) 849-856.

[18] J.K. Reddy, T.P. Krishnakantha, Hepatic peroxisome proliferation: induction by two novel compounds structurally unrelated to clofibrate, Science 190 (1975) 787-789.

[19] S.S. Lee, T. Pineau, J. Drago, E.J. Lee, J.W. Owens, D.L. Kroetz, P.M. FernandezSalguero, H. Westphal, F.J. Gonzalez, Targeted disruption of the alpha isoform of the 
Fidaleo et al., ThB and genes of cholesterol biosynthesis in liver

peroxisome proliferator-activated receptor gene in mice results in abolishment of the pleiotropic effects of peroxisome proliferators, Mol. Cell. Biol. 15 (1995) 3012-3022. [20] I. Issemann, S. Green, Activation of a member of the steroid hormone receptor superfamily by peroxisome proliferators, Nature 347 (1990) 645-650.

[21] P.R. Devchand, H. Keller, J.M. Peters, M. Vazquez, F.J. Gonzalez, W. Wahli, The PPARalpha-leukotriene B4 pathway to inflammation control, Nature 384 (1996) 39-43. [22] P. Escher, O. Braissant, S. Basu-Modak, L. Michalik, W. Wahli, B. Desvergne, Rat PPARs: quantitative analysis in adult rat tissues and regulation in fasting and refeeding, Endocrinology 142 (2001) 4195-4202.

[23] S. Mandard, M. Muller, S. Kersten, Peroxisome proliferator-activated receptor alpha target genes, Cell. Mol. Life Sci. 61 (2004) 393-416.

[24] F. Hansmannel, M.C. Clemencet, C. Le Jossic-Corcos, T. Osumi, N. Latruffe, V. Nicolas-Frances, Functional characterization of a peroxisome proliferator response-element located in the intron 3 of rat peroxisomal thiolase B gene, Biochem. Biophys. Res. Commun. 311 (2003) 149-155.

[25] V. Nicolas-Frances, V.K. Dasari, E. Abruzzi, T. Osumi, N. Latruffe, The peroxisome proliferator response element (PPRE) present at positions -681/-669 in the rat liver 3-ketoacylCoA thiolase B gene functionally interacts differently with PPARalpha and HNF-4, Biochem. Biophys. Res. Commun. 269 (2000) 347-351.

[26] B. Desvergne, W. Wahli, Peroxisome proliferator-activated receptors: nuclear control of metabolism, Endocr. Rev. 20 (1999) 649-688.

[27] F.J. Gonzalez, Y.M. Shah, PPARalpha: mechanism of species differences and hepatocarcinogenesis of peroxisome proliferators, Toxicology 246 (2008) 2-8.

[28] R. Genolet, W. Wahli, L. Michalik, PPARs as drug targets to modulate inflammatory responses? Curr. Drug Targets Inflamm. Allergy 3 (2004) 361-375.

[29] R. Stienstra, S. Mandard, N.S. Tan, W. Wahli, C. Trautwein, T.A. Richardson, E. Lichtenauer-Kaligis, S. Kersten, M. Muller, The Interleukin-1 receptor antagonist is a direct target gene of PPARalpha in liver, J. Hepatol. 46 (2007) 869-877.

[30] M. Cherkaoui-Malki, K. Meyer, W.Q. Cao, N. Latruffe, A.V. Yeldandi, M.S. Rao, C.A. Bradfield, J.K. Reddy, Identification of novel peroxisome proliferator-activated receptor alpha (PPARalpha) target genes in mouse liver using cDNA microarray analysis, Gene Expr. 9 (2001) 291-304.

[31] L.M. Sanderson, P.J. de Groot, G.J. Hooiveld, A. Koppen, E. Kalkhoven, M. Muller, S. Kersten, Effect of synthetic dietary triglycerides: a novel research paradigm for nutrigenomics, PLoS One 3 (2008) e1681.

[32] Z.Y. Du, L. Demizieux, P. Degrace, J. Gresti, B. Moindrot, Y.J. Liu, L.X. Tian, J.M. Cao, P. Clouet, Alteration of 20:5n-3 and 22:6n-3 fat contents and liver peroxisomal activities in fenofibrate-treated rainbow trout, Lipids 39 (2004) 849-855.

[33] P. Degrace, L. Demizieux, J. Gresti, J.M. Chardigny, J.L. Sebedio, P. Clouet, Hepatic steatosis is not due to impaired fatty acid oxidation capacities in C57BL/6J mice fed the conjugated trans-10,cis-12-isomer of linoleic acid, J. Nutr. 134 (2004) 861-867.

[34] H. Weissbach, T.E. Smith, J.W. Daly, B. Witkop, S. Udenfriend, A rapid spectrophotometric assay of mono-amine oxidase based on the rate of disappearance of kynuramine, J. Biol. Chem. 235 (1960) 1160-1163.

[35] J.B. Robinson, Jr., P.A. Srere, Organization of Krebs tricarboxylic acid cycle enzymes in mitochondria, J. Biol. Chem. 260 (1985) 10800-10805.

[36] M. Bronfman, N.C. Inestrosa, F. Leighton, Fatty acid oxidation by human liver peroxisomes, Biochem. Biophys. Res. Commun. 88 (1979) 1030-1036.

[37] F. Roels, B. De Prest, G. De Pestel, Liver and chorion cytochemistry, J. Inherit. Metab. Dis. 18 Suppl 1 (1995) 155-171.

[38] I. Kerckaert, D. De Craemer, G. Van Limbergen, Practical guide for morphometry of human peroxisomes on electron micrographs, J. Inherit. Metab. Dis. 18 Suppl 1 (1995) 172180. 
Fidaleo et al., ThB and genes of cholesterol biosynthesis in liver

[39] S. Mandard, R. Stienstra, P. Escher, N.S. Tan, I. Kim, F.J. Gonzalez, W. Wahli, B. Desvergne, M. Muller, S. Kersten, Glycogen synthase 2 is a novel target gene of peroxisome proliferator-activated receptors, Cell. Mol. Life Sci. 64 (2007) 1145-1157.

[40] G. Denis, S. Mandard, C. Humblet, M. Verlaet, J. Boniver, D. Stehelin, M.P. Defresne, D. Regnier, Nuclear localization of a new c-cbl related protein, CARP 90, during in vivo thymic apoptosis in mice, Cell. Death Differ. 6 (1999) 689-697.

[41] S. Hogenboom, G.J. Romeijn, S.M. Houten, M. Baes, R.J. Wanders, H.R. Waterham, Absence of functional peroxisomes does not lead to deficiency of enzymes involved in cholesterol biosynthesis, J. Lipid. Res. 43 (2002) 90-98.

[42] S. Miyazawa, T. Osumi, T. Hashimoto, The presence of a new 3-oxoacyl-CoA thiolase in rat liver peroxisomes, Eur. J. Biochem. 103 (1980) 589-596.

[43] M. Baarine, K. Ragot, E.C. Genin, H. El Hajj, D. Trompier, P. Andreoletti, M.S. Ghandour, F. Menetrier, M. Cherkaoui-Malki, S. Savary, G. Lizard, Peroxisomal and mitochondrial status of two murine oligodendrocytic cell lines $(158 \mathrm{~N}, 158 \mathrm{JP})$ : potential models for the study of peroxisomal disorders associated with dysmyelination processes, J. Neurochem. 111 (2009) 119-131.

[44] C. Le Jossic-Corcos, S. Duclos, L.C. Ramirez, I. Zaghini, G. Chevillard, P. Martin, T. Pineau, P. Bournot, Effects of peroxisome proliferator-activated receptor alpha activation on pathways contributing to cholesterol homeostasis in rat hepatocytes, Biochim. Biophys. Acta 1683 (2004) 49-58.

[45] B.L. Knight, A. Hebbachi, D. Hauton, A.M. Brown, D. Wiggins, D.D. Patel, G.F. Gibbons, A role for PPARalpha in the control of SREBP activity and lipid synthesis in the liver, Biochem. J. 389 (2005) 413-421.

[46] D.D. Hinson, K.L. Chambliss, M.J. Toth, R.D. Tanaka, K.M. Gibson, Post-translational regulation of mevalonate kinase by intermediates of the cholesterol and nonsterol isoprene biosynthetic pathways, J Lipid Res 38 (1997) 2216-2223.

[47] H.J. Kempen, J.F. Glatz, J.A. Gevers Leuven, H.A. van der Voort, M.B. Katan, Serum lathosterol concentration is an indicator of whole-body cholesterol synthesis in humans, J. Lipid. Res. 29 (1988) 1149-1155.

[48] J.J. Hamilton, M. Phang, S.M. Innis, Elevation of plasma lathosterol, as an indicator of increased cholesterol synthesis, in preterm (23-32 weeks gestation) infants given Intralipid, Pediatr. Res. 31 (1992) 186-192.

[49] S. Arnauld, M. Fidaleo, M.C. Clemencet, G. Chevillard, A. Athias, J. Gresti, R.J. Wanders, N. Latruffe, V. Nicolas-Frances, S. Mandard, Modulation of the hepatic fatty acid pool in peroxisomal 3-ketoacyl-CoA thiolase B-null mice exposed to the selective PPARalpha agonist Wy14,643, Biochimie 91 (2009) 1376-1386.

[50] E. Baumgart, I. Vanhorebeek, M. Grabenbauer, M. Borgers, P.E. Declercq, H.D. Fahimi, M. Baes, Mitochondrial alterations caused by defective peroxisomal biogenesis in a mouse model for Zellweger syndrome (PEX5 knockout mouse), Am. J. Pathol. 159 (2001) 1477-1494.

[51] P.L. Faust, M.E. Hatten, Targeted deletion of the PEX2 peroxisome assembly gene in mice provides a model for Zellweger syndrome, a human neuronal migration disorder, J. Cell. Biol. 139 (1997) 1293-1305.

[52] M. Funato, N. Shimozawa, T. Nagase, Y. Takemoto, Y. Suzuki, Y. Imamura, T. Matsumoto, T. Tsukamoto, T. Kojidani, T. Osumi, T. Fukao, N. Kondo, Aberrant peroxisome morphology in peroxisomal beta-oxidation enzyme deficiencies, Brain Dev. 28 (2006) 287-292. [53] M. Schrader, E. Baumgart, A. Volkl, H.D. Fahimi, Heterogeneity of peroxisomes in human hepatoblastoma cell line HepG2. Evidence of distinct subpopulations, Eur. J. Cell. Biol. 64 (1994) 281-294.

[54] F. Roels, M. Pauwels, B.T. Poll-The, J. Scotto, H. Ogier, P. Aubourg, J.M. Saudubray, Hepatic peroxisomes in adrenoleukodystrophy and related syndromes: cytochemical and morphometric data, Virchows Arch. A. Pathol. Anat. Histopathol. 413 (1988) 275-285. 
Fidaleo et al., ThB and genes of cholesterol biosynthesis in liver

[55] P. Brites, A.M. Motley, P. Gressens, P.A. Mooyer, I. Ploegaert, V. Everts, P. Evrard, P. Carmeliet, M. Dewerchin, L. Schoonjans, M. Duran, H.R. Waterham, R.J. Wanders, M. Baes, Impaired neuronal migration and endochondral ossification in Pex7 knockout mice: a model for rhizomelic chondrodysplasia punctata, Hum. Mol. Genet. 12 (2003) 2255-2267.

[56] V.D. Antonenkov, P.P. Van Veldhoven, E. Waelkens, G.P. Mannaerts, Comparison of the stability and substrate specificity of purified peroxisomal 3-oxoacyl-CoA thiolases A and B from rat liver, Biochim Biophys Acta 1437 (1999) 136-141.

[57] Y. Jia, C. Qi, Z. Zhang, T. Hashimoto, M.S. Rao, S. Huyghe, Y. Suzuki, P.P. Van Veldhoven, M. Baes, J.K. Reddy, Overexpression of peroxisome proliferator-activated receptor-alpha (PPARalpha)-regulated genes in liver in the absence of peroxisome proliferation in mice deficient in both L- and D-forms of enoyl-CoA hydratase/dehydrogenase enzymes of peroxisomal beta-oxidation system, J. Biol. Chem. 278 (2003) 47232-47239.

[58] R. Dirkx, E. Meyhi, S. Asselberghs, J. Reddy, M. Baes, P.P. Van Veldhoven, Betaoxidation in hepatocyte cultures from mice with peroxisomal gene knockouts, Biochem. Biophys. Res. Commun. 357 (2007) 718-723.

[59] T. Kasumov, J.E. Adams, F. Bian, F. David, K.R. Thomas, K.A. Jobbins, P.E. Minkler, C.L. Hoppel, H. Brunengraber, Probing peroxisomal beta-oxidation and the labelling of acetylCoA proxies with [1-(13C)]octanoate and [3-(13C)]octanoate in the perfused rat liver, Biochem J 389 (2005) 397-401.

[60] N. Aboushadi, W.H. Engfelt, V.G. Paton, S.K. Krisans, Role of peroxisomes in isoprenoid biosynthesis, J. Histochem. Cytochem. 47 (1999) 1127-1132.

[61] W.J. Kovacs, K.N. Tape, J.E. Shackelford, X. Duan, T. Kasumov, J.K. Kelleher, H. Brunengraber, S.K. Krisans, Localization of the pre-squalene segment of the isoprenoid biosynthetic pathway in mammalian peroxisomes, Histochem. Cell Biol. 127 (2007) 273-290. [62] I. Weinhofer, M. Kunze, H. Stangl, F.D. Porter, J. Berger, Peroxisomal cholesterol biosynthesis and Smith-Lemli-Opitz syndrome, Biochem Biophys Res Commun 345 (2006) 205-209.

[63] W.J. Kovacs, K.N. Tape, J.E. Shackelford, T.M. Wikander, M.J. Richards, S.J. Fliesler, S.K. Krisans, P.L. Faust, Peroxisome deficiency causes a complex phenotype because of hepatic SREBP/Insig dysregulation associated with endoplasmic reticulum stress, J Biol Chem 284 (2009) 7232-7245.

[64] D.L. van der Meer, T. Degenhardt, S. Vaisanen, P.J. de Groot, M. Heinaniemi, S.C. de Vries, M. Muller, C. Carlberg, S. Kersten, Profiling of promoter occupancy by PPAR $\{$ alpha $\}$ in human hepatoma cells via ChIP-chip analysis, Nucleic. Acids Res. (2010).

[65] N. Leuenberger, S. Pradervand, W. Wahli, Sumoylated PPARalpha mediates sexspecific gene repression and protects the liver from estrogen-induced toxicity in mice, J. Clin. Invest. 119 (2009) 3138-3148.

[66] J.D. Horton, J.L. Goldstein, M.S. Brown, SREBPs: activators of the complete program of cholesterol and fatty acid synthesis in the liver, J. Clin. Invest. 109 (2002) 1125-1131. [67] J.D. Horton, I. Shimomura, Sterol regulatory element-binding proteins: activators of cholesterol and fatty acid biosynthesis, Curr. Opin. Lipidol. 10 (1999) 143-150.

[68] J.D. Horton, I. Shimomura, M.S. Brown, R.E. Hammer, J.L. Goldstein, H. Shimano, Activation of cholesterol synthesis in preference to fatty acid synthesis in liver and adipose tissue of transgenic mice overproducing sterol regulatory element-binding protein-2, J. Clin. Invest. 101 (1998) 2331-2339.

[69] H. Shimano, J.D. Horton, I. Shimomura, R.E. Hammer, M.S. Brown, J.L. Goldstein, Isoform 1c of sterol regulatory element binding protein is less active than isoform 1a in livers of transgenic mice and in cultured cells, J. Clin. Invest. 99 (1997) 846-854.

[70] M. Arito, T. Horiba, S. Hachimura, J. Inoue, R. Sato, Growth factor-induced phosphorylation of sterol regulatory element-binding proteins inhibits sumoylation, thereby stimulating the expression of their target genes, low density lipoprotein uptake, and lipid synthesis, J Biol Chem 283 (2008) 15224-15231. 
Fidaleo et al., ThB and genes of cholesterol biosynthesis in liver

[71] M. Rakhshandehroo, L.M. Sanderson, M. Matilainen, R. Stienstra, C. Carlberg, P.J. de Groot, M. Muller, S. Kersten, Comprehensive Analysis of PPARalpha-Dependent Regulation of Hepatic Lipid Metabolism by Expression Profiling, PPAR Res 2007 (2007) 26839. [72] Y. Wang, P.M. Rogers, C. Su, G. Varga, K.R. Stayrook, T.P. Burris, Regulation of cholesterologenesis by the oxysterol receptor, LXRalpha, J. Biol. Chem. 283 (2008) 2633226339.

[73] K.A. Tobin, H.H. Steineger, S. Alberti, O. Spydevold, J. Auwerx, J.A. Gustafsson, H.I. Nebb, Cross-talk between fatty acid and cholesterol metabolism mediated by liver X receptoralpha, Mol. Endocrinol. 14 (2000) 741-752.

[74] J. Lengqvist, A. Mata De Urquiza, A.C. Bergman, T.M. Willson, J. Sjovall, T. Perlmann, W.J. Griffiths, Polyunsaturated fatty acids including docosahexaenoic and arachidonic acid bind to the retinoid X receptor alpha ligand-binding domain, Mol. Cell. Proteomics 3 (2004) 692-703.

[75] H. Cao, K. Gerhold, J.R. Mayers, M.M. Wiest, S.M. Watkins, G.S. Hotamisligil, Identification of a lipokine, a lipid hormone linking adipose tissue to systemic metabolism, Cell 134 (2008) 933-944.

[76] M.T. Flowers, M.P. Keller, Y. Choi, H. Lan, C. Kendziorski, J.M. Ntambi, A.D. Attie, Liver gene expression analysis reveals endoplasmic reticulum stress and metabolic dysfunction in SCD1-deficient mice fed a very low-fat diet, Physiol Genomics 33 (2008) 361-372. [77] C.M. Paton, J.M. Ntambi, Loss of stearoyl-CoA desaturase activity leads to free cholesterol synthesis through increased Xbp-1 splicing, Am J Physiol Endocrinol Metab.

[78] W.J. Kovacs, J.E. Shackelford, K.N. Tape, M.J. Richards, P.L. Faust, S.J. Fliesler, S.K. Krisans, Disturbed cholesterol homeostasis in a peroxisome-deficient PEX2 knockout mouse model, Mol. Cell. Biol. 24 (2004) 1-13.

\section{Figure 1. Peroxisomal $\beta$-oxidation of $\left(1-{ }^{14} \mathrm{C}\right)$ palmitate is impaired in $T h b^{-/-}$mice treated with}

\section{Wy, a potent PPAR $\alpha$ agonist.}

WT and $T h b^{-/-}$mice were treated with Wy $(30 \mathrm{mg} / \mathrm{kg}$ of body weight) for 8 days or left untreated. At the end of the pharmacological intervention, the animals were fasted (starting at 4 a.m) for 6 hours before sacrifice a) Liver RNA (5 animals were used for each condition) was isolated and RT-qPCR was performed. Gene expression levels from the animals receiving vehicle only were set at 1 . Thb: peroxisomal 3-ketoacyl-CoA thiolase B ; Tha: peroxisomal 3-ketoacyl-CoA thiolase A b) Western blot analysis of PTL (anti-peroxisomal 3-ketoacyl-CoA thiolase A and B proteins) in liver protein extracts from five animals. $\beta$-actin was used as a loading control marker c) Liver RNA was isolated and RT-qPCR was performed (From 6 to 20 animals were used per condition). Gene expression levels from the animals receiving vehicle only were set at 1. Acox 1: peroxisomal Acyl-CoA oxidase 1; Mfp-1: Multifunctional protein 1; $S c p x / S c p 2$ thiolase: Sterol carrier protein $\mathrm{x} / 2$ thiolase; Values are expressed as mean \pm SEM. See supplemental data, Table 2 for primer sequences. d) 
Fidaleo et al., ThB and genes of cholesterol biosynthesis in liver

1 Western blot analysis of Acox 1 in liver protein extracts from five animals. $\beta$-actin was used as a

2 loading control marker e) Peroxisomal $\left(1-{ }^{14} \mathrm{C}\right)$ palmitate $\beta$-oxidation and f) NADH production were

3 quantified in vitro using whole liver homogenates from WT and $T h b^{-/}$mice $(\mathrm{n}=3)$ Values are

4 expressed as mean \pm SEM. Statistically significant differences were calculated using a two-way

5 ANOVA for genotype (G), Wy14,643 (Wy) and the interaction between the two parameters (I).

6

7 Figure 2. Mitochondrial $\beta$-oxidation of $\left(1-{ }^{14} \mathrm{C}\right)$ palmitate is not compromised in $\mathrm{Thb}^{-/-}$mice

8 treated with the potent PPAR $\alpha$ agonist, $W y$.

9 (a) Mitochondrial $\left(1-{ }^{14} \mathrm{C}\right)$ palmitate $\beta$-oxidation in liver homogenates (b) Mitochondrial $\left(1-{ }^{14} \mathrm{C}\right)$

10 palmitate $\beta$-oxidation in mitochondrial fractions. WT and $T h b^{-/}$mice were treated with $\mathrm{Wy}$

$11(30 \mathrm{mg} / \mathrm{kg}$ of body weight) for 8 days, or left untreated. At the end of the pharmacological

12 intervention, the animals were fasted (starting at 4 a.m) for 6 hours before sacrifice. Three animals

13 were used per condition. Values are expressed as mean \pm SEM. Statistically significant differences

14 were calculated using a two-way ANOVA for genotype (G), Wy14,643 (Wy) and the interaction

15 between the two parameters (I).

17 Figure 3. Thb Deletion did not prevent $\mathbf{W y}$-induced cell-size increase and cell proliferation 18 rates.

19 (a) Hepato-somatic index of Wy-treated (30 mg/kg of body weight, 8 days) or mock-treated WT

20 and $T h b^{-/}$mice. Five to ten animals were used per group. Error bars represent \pm SEM. Statistically

21 significant differences were calculated using a two-way ANOVA for genotype (G), Wy14,643

22 (Wy) and the interaction between the two parameters (I) (b) Mean cell number/field and cell

23 surface in the liver of WT mice and $T h b^{-/}$mice (c) Hematoxylin and eosin staining of

24 representative mouse liver sections showing increased hepatocyte size following Wy-treatment.

25 Scale bar, $20 \mu \mathrm{m}$. (d) Immunohistochemical staining for Ki-67 in hepatocyte nuclei in liver

26 sections from Wy-treated and mock-treated WT and $T h b^{-/-}$mice. Scale bar, $20 \mu \mathrm{m}$. 
Fidaleo et al., ThB and genes of cholesterol biosynthesis in liver

1 Figure 4. $T h b$ deletion did not prevent $\mathrm{Wy}$-induced peroxisome proliferation.

2 (a-d) Immunohistochemical staining of peroxisomes in the liver. Light microscopy of semithin

3 liver sections from 3-month-old mice after incubation with the alkaline DAB-medium to

4 demonstrate catalase activity; arrows indicate some hepatocyte nuclei. (a) Liver from a WT mouse,

5 showing a distinct granular staining pattern, reflecting normal peroxisome distribution (c) A similar

6 staining pattern is found in the liver of a $T h b^{-/-}$mouse ( $b$ and $\mathrm{d}$ ) Peroxisome proliferation is

7 prominent after Wy-treatment in WT and $T h b^{-/-}$mice (e) Liver RNA was isolated and RT-qPCR

8 was performed $(n=6)$. Gene expression levels from the animals receiving vehicle only were set at

9 1. Statistically significant differences were calculated using a two-way ANOVA for genotype (G),

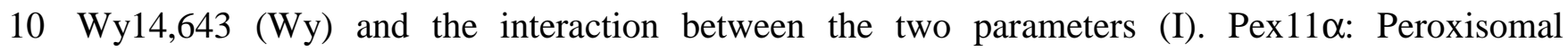

11 biogenesis factor $11 \alpha$; (f-i) Representative electron micrographs of mouse-liver sections without

12 treatment $(\mathrm{f}, \mathrm{h})$ and after Wy-treatment $(\mathrm{g}, \mathrm{i})$. Note the presence of peroxisomes with a slightly

13 elongated shape (see arrows) in $\mathrm{h}$ in contrast to the rounded shapes in f. Glycogen rosettes, specific

14 for hepatic parenchyma were present in many cells. M: Mitochondria.

16 Figure 5: Heat map showing changes in expression of selected genes encoding for cholesterol

17 biosynthesis enzymes in the liver as determined by microarray.

18 WT and $T h b^{-/-}$mice were treated with Wy (30 mg/kg/day for 8 days) or left untreated, and all

19 animals were fasted for $6 \mathrm{~h}$ prior to sacrifice. Pooled liver RNA ( $\mathrm{n}=5)$ was hybridized on

20 Affymetrix GeneChip Mouse Genome 430A arrays. Expression levels were analyzed using

21 Microarray Suite and Data Mining Tool software, as previously described [29]. The heat map was

22 generated directly from the microarray data. The expression signals from the mock-treated WT

23 animals were arbitrarily set at 1 and the scale represents fold-induction relative to mock-treated WT

24 mice. The selected genes exceeded minimal threshold expression levels. 
Fidaleo et al., ThB and genes of cholesterol biosynthesis in liver

1 Figure 6: The hepatic expression of genes involved in de novo cholesterol biosynthesis is

2 impaired in Wy-treated $\boldsymbol{T h}^{-/-}$mice. WT $(\mathrm{n}=5)$ and $\operatorname{Thb}^{-/-}(\mathrm{n}=5)$ mice were treated with Wy

$3(30 \mathrm{mg} / \mathrm{kg}$ of body weight, 8 days), or left untreated. All animals were fasted for $6 \mathrm{~h}$ prior to

4 sacrifice. Liver RNA was isolated and RT-qPCR was performed. Gene expression levels from the

5 animals receiving vehicle only were set at 1 . Hmgcs1 : cytosolic 3-hydroxy-3-methylglutaryl

6 coenzyme A (HMG-CoA) synthase-1, Hmgcr : microsomal 3-hydroxy-3-methylglutaryl coenzyme

7 A (HMG-CoA) reductase, Mvk: mevalonate kinase, Pmvk: phosphomevalonate kinase,

8 mvd: mevalonate decarboxylase, $F d p s$ : farnesyl diphosphate synthase, $F d f t 1$ : farnesyl-diphosphate

9 farnesyltransferase-1, Sqls: squalene synthase, sqle: squalene epoxidase, Lss: lanosterol synthase,

10 Cyp 51: sterol 14 alpha-demethylase, $N s d h l$ : $\mathrm{NAD}(\mathrm{P})$ dependent steroid dehydrogenase-like, $S c 5 d$ :

11 sterol-C5-desaturase, Dhcr7: 7-dehydrocholesterol reductase. Error bars represent \pm SEM.

12 Statistically significant differences were calculated using a two-way ANOVA for genotype (G),

13 Wy14,643 (Wy) and the interaction between the two parameters (I). See supplemental data, Table 2

14 for primer sequences.

16 Figure 7: The hepatic expression of genes involved in de novo cholesterol biosynthesis is

17 impaired in fenofibrate-treated $\boldsymbol{T h b}^{-/-}$mice.

18 WT $(\mathrm{n}=5)$ and $T h b^{-/}(\mathrm{n}=5)$ mice were previously treated with fenofibrate $(100 \mathrm{mg} / \mathrm{kg}$ of body

19 weight) for 14 days, or left untreated. All animals were fasted for $6 \mathrm{~h}$ prior to sacrifice. Liver RNA

20 was isolated and RT-qPCR was performed. Gene expression levels from the animals receiving

21 vehicle only were set at 1 . Hmgcs1 : cytosolic 3-hydroxy-3-methylglutaryl coenzyme A (HMG-

22 CoA) synthase-1, Hmgcr : microsomal 3-hydroxy-3-methylglutaryl coenzyme A (HMG-CoA)

23 reductase, Mvk: mevalonate kinase, Pmvk: phosphomevalonate kinase, $M v d$ : mevalonate

24 decarboxylase, Sqls: squalene synthase, Srebplc: sterol response element binding protein-1c,

25 Ppar $\alpha$ : peroxisome proliferator-activated receptor alpha, FF: Fenofibrate. Statistically significant 
Fidaleo et al., ThB and genes of cholesterol biosynthesis in liver

1 differences were calculated using a two-way ANOVA for genotype (G), fenofibrate (FF) and the

2 interaction between the two parameters (I). See supplemental data, Table 2 for primer sequences.

3

4

5 Wy-treated $\boldsymbol{T h} \boldsymbol{h}^{-/-}$mice (a) Pooled total liver cell lysates from Wy-treated or mock-treated WT and

$6 \mathrm{Thb}^{-/}$mice $(30 \mathrm{mg} / \mathrm{kg}$ of body weight, 8 days) and fasted for $6 \mathrm{~h}$ prior to sacrifice. Analyses for

7 mouse HMG-CoA reductase, Mvk and Pmvk protein content were conducted by Western blotting,

8 using polyclonal antibodies. There were 5 animals per group except for the WT group $(\mathrm{n}=10)$.

9 Molecular mass sizes are given in $\mathrm{kDa}$. Quantification of bands relative to $\beta$-actin controls is given

10 under each picture (b) Western blot analysis of PPAR $\alpha$ was performed on nuclear extracts from the

11 livers of five animals. Cellular lysates of COS-7 cells transfected with the expression vector pSG5

12 PPAR $\alpha$ were used as a positive control. Histone H1 was used as a loading control marker (c) WT

$13(\mathrm{n}=5)$ and $T h b^{-/-}(\mathrm{n}=5)$ mice were treated with Wy for 8 days or left untreated. All animals were

14 fasted for 6h prior to sacrifice. Liver RNA was isolated and RT-qPCR was performed for Srebp-2.

15 Statistically significant differences were calculated using a two-way ANOVA for genotype (G),

16 Wy14,643 (Wy) and the interaction between the two parameters (I). Pooled nuclear extracts from

17 mock-treated or Wy- or fenofibrate-treated WT and $T h b^{-/-}$mice were analyzed by Western blotting

18 for the mouse mature form of the transcription factor SREBP-2 (right part). Histone H1 or Tata-

19 Binding Protein (TBP) were used for normalization of nuclear proteins. Wy: Wy14,643, FF:

20 Fenofibrate.

22 Figure 9: De novo whole body cholesterol biosynthesis is equally reduced by activated PPAR $\alpha$

23 in both WT mice and $T h b^{-/}$mice.

24 a) Plasma lathosterol/cholesterol ratio in mock-treated and Wy-treated WT and $T h b^{-/-}$mice $(\mathrm{n}=5$

25 per condition) and fasted for $6 \mathrm{~h}$ prior to sacrifice $\mathrm{b}$ ) Total and free cholesterol in liver ( $\mathrm{n}=5$ to 10

26 mice per group) c) liver lathosterol/cholesterol ratio and d) total cholesterol in mock-treated and 
Fidaleo et al., ThB and genes of cholesterol biosynthesis in liver

1 fenofibrate-treated WT and $T h b^{-/}$mice and fasted for 6 h prior to sacrifice ( $\mathrm{n}=4$ per condition).

2 Error bars represent \pm SEM. Statistically significant differences were calculated using a two-way

3 ANOVA for genotype (G), Wy14,643 (Wy) and the interaction between the two parameters (I).

5 Table 1. Mitochondrial marker enzyme activities in the liver are not affected by the deletion

6 of $\boldsymbol{T h} \boldsymbol{b}$ in mice. Carnitine Palmitoyl Transferase-1 alpha (CPT-I $\alpha$ ), monoamine oxidase, citrate

7 synthase activities were measured in purified mitochondria. Wy: Wy14,643. Number of animals

8 per group is indicated. Mice in the fed state were sacrificed at the beginning of the light cycle. For

9 the fasting experiment, male mice were fasted for 24 hours starting at the onset of the light cycle.

10 Statistically significant differences were calculated using a two-way ANOVA for genotype (G),

11 Wy14,643 (Wy), fasting (F) and interaction between the two parameters (I).

13 Supplemental Figure 1.

14 Similar levels of typical PPAR $\alpha$ target gene induction were observed in the livers of WT and

$15 \boldsymbol{T h}^{-/-}$mice treated with two different PPAR $\alpha$ agonists. a) mock-treated and Wy-treated

16 (30mg/kg of body weight for 8 days) WT and $T h b^{-/-}$mice and fasted for $6 \mathrm{~h}$ prior to sacrifice b)

17 mock-treated and fenofibrate-treated $\left(100 \mathrm{mg} / \mathrm{kg}\right.$ of body weight for 14 days) WT and $T h b^{-/}$mice

18 and fasted for 6h prior to sacrifice. Liver RNA was isolated and RT-qPCR was performed. Five to

19 eight animals were used for each condition. Gene expression levels from the animals receiving

20 vehicle only were set at 1 . See supplemental Table 2 for primer sequences. FF: Fenofibrate. Wy:

21 Wy14,643. Acot3: Acyl-CoA thioesterase 3; Pdk4: Pyruvate dehydrogenase kinase-4; Fat/Cd36:

22 Fatty acid translocase; $a$-Fabp: adipose-Fatty acid binding protein (also known as aP2); Thb:

23 Thiolase B; Cyp4a10: Cytochrome p450A10; Lpl: Lipoprotein Lipase; Fatp-1: Fatty acid transport241. 
Fidaleo et al., ThB and genes of cholesterol biosynthesis in liver

1

\section{Supplemental Table 1.}

3 Micro-array analysis was performed on pooled liver $(n=5)$ mRNA comparing the gene expression

4 signals induced by the deletion of $T h b$ and by pharmacological intervention (Wy, $30 \mathrm{mg} / \mathrm{kg}$ of body

5 weight/ 8 days). Column $\mathrm{C}$ to F: Expression in mock-treated WT mice was arbitrarily set at 1.

6 Changes in gene expression are expressed as fold-changes in comparison with mock-treated WT

7 mice, receiving vehicle only.

8

\section{Supplemental Table 2.}

10 Primer sequences used for Real-Time Quantitative PCR.

11

12

13

14

15

16

17

18

19

20

21

22

23

24

25

26

27

28

29

30 
Fidaleo et al., ThB and genes of cholesterol biosynthesis in liver

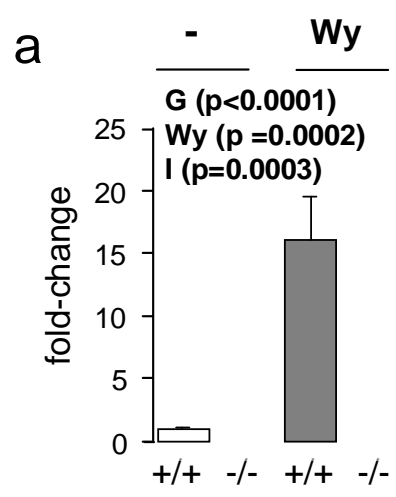

Thb

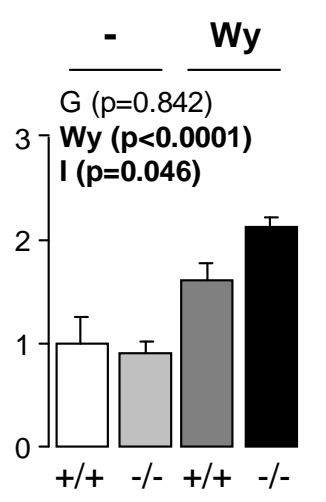

Tha b

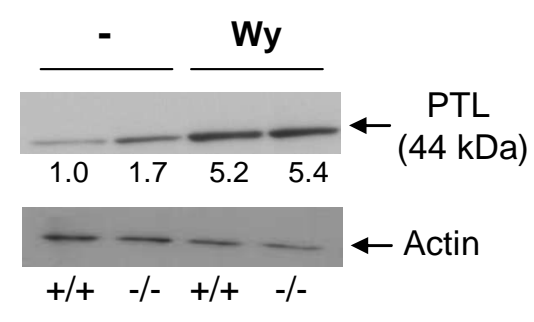

d

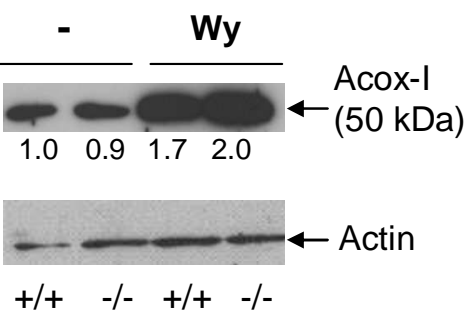

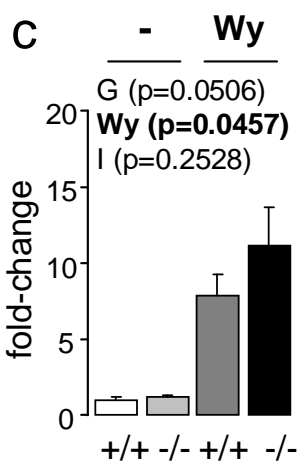

Acox-I

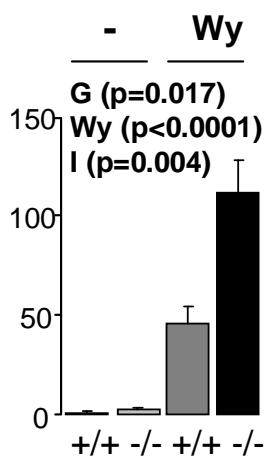

Mfp-1

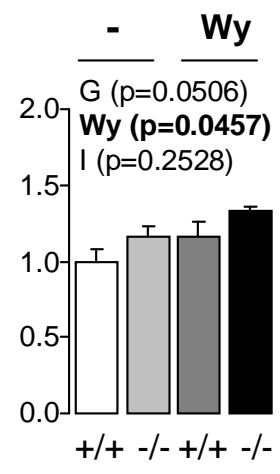

Scpx/Scp2 e

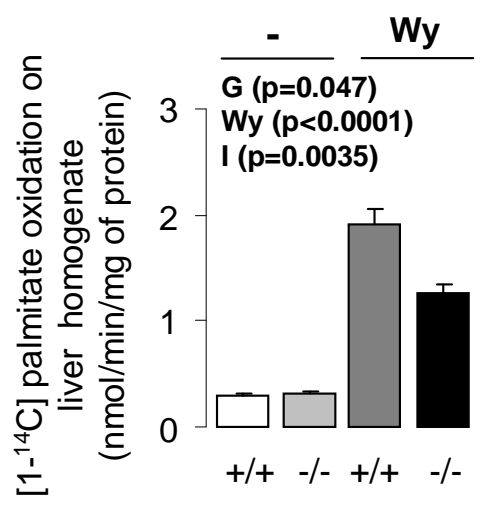

f

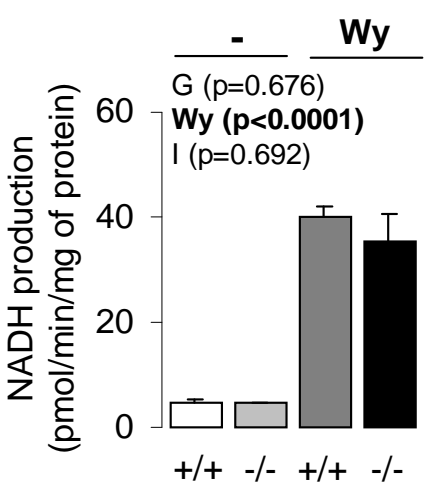

Fidaleo et al., Figure 1 
Fidaleo et al., ThB and genes of cholesterol biosynthesis in liver

2

3

a

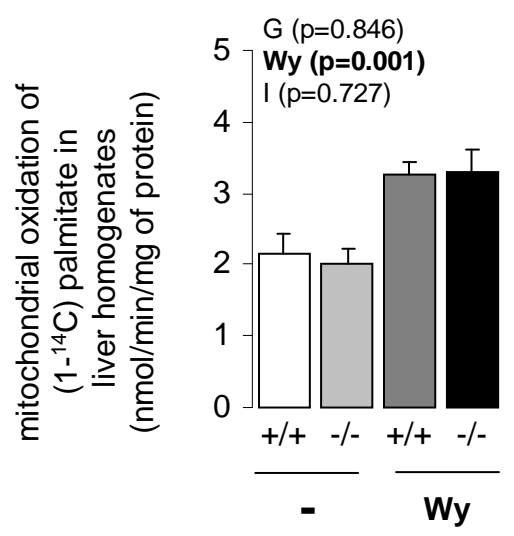

4

5

6

7

8

9

10

11

12

13

14

15

16

17

18

19

20

21

22

23

24

25

26

27

28

29

30

31

32

33

34

35

36

37 b

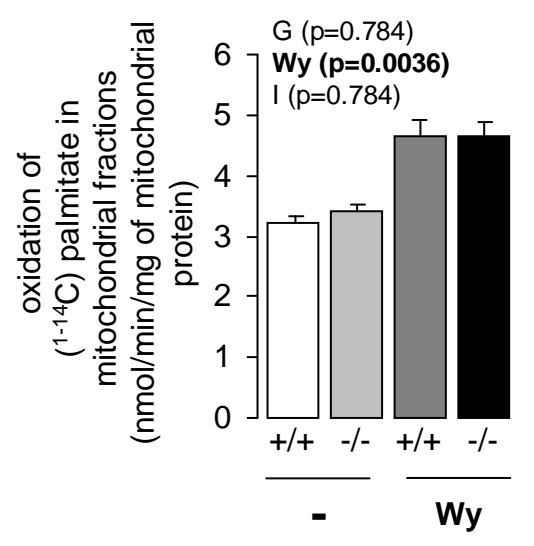

Fidaleo et al., Figure 2 
Fidaleo et al., ThB and genes of cholesterol biosynthesis in liver

a

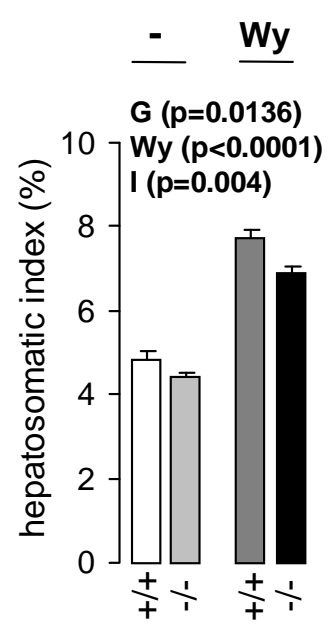

b

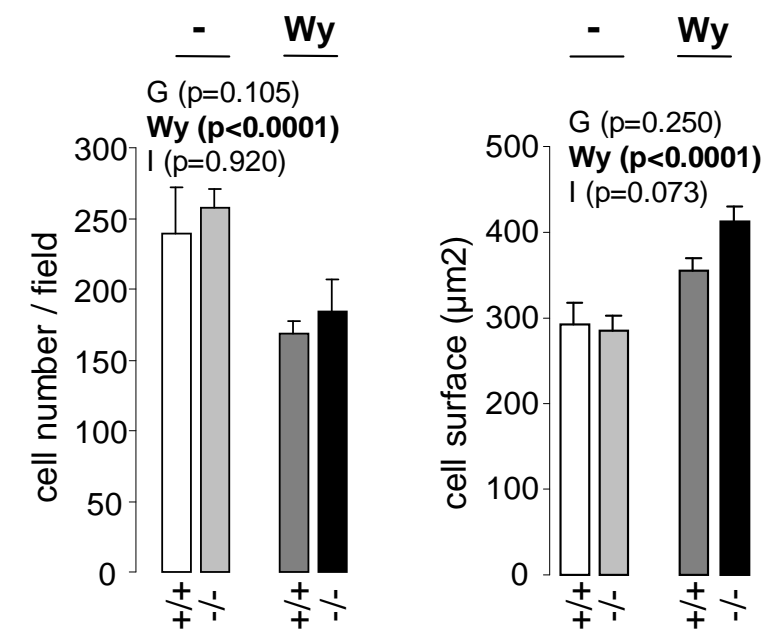

C
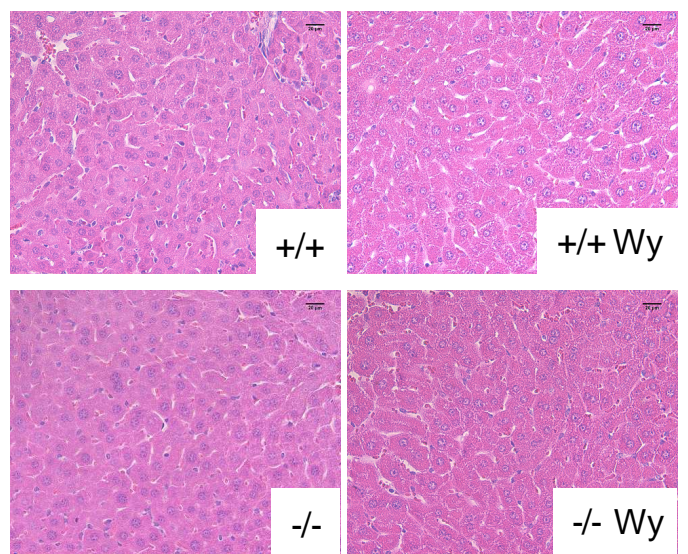

$-/-W y$ d

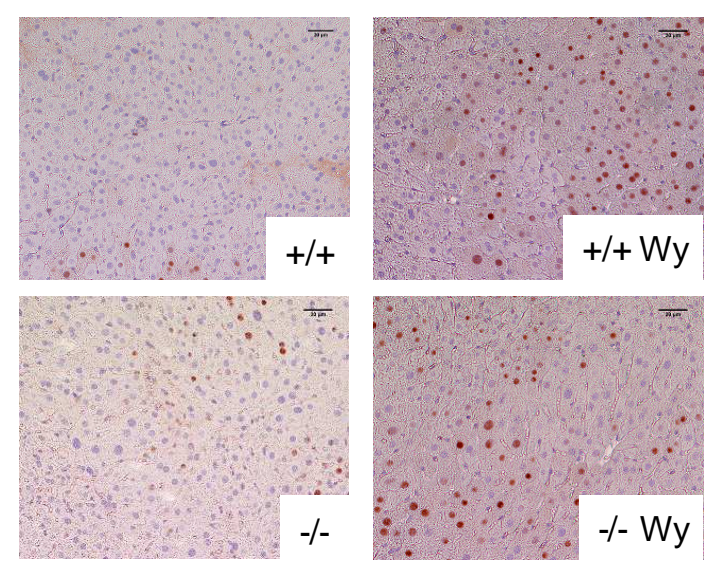

Fidaleo et al., Figure 3 
Fidaleo et al., ThB and genes of cholesterol biosynthesis in liver
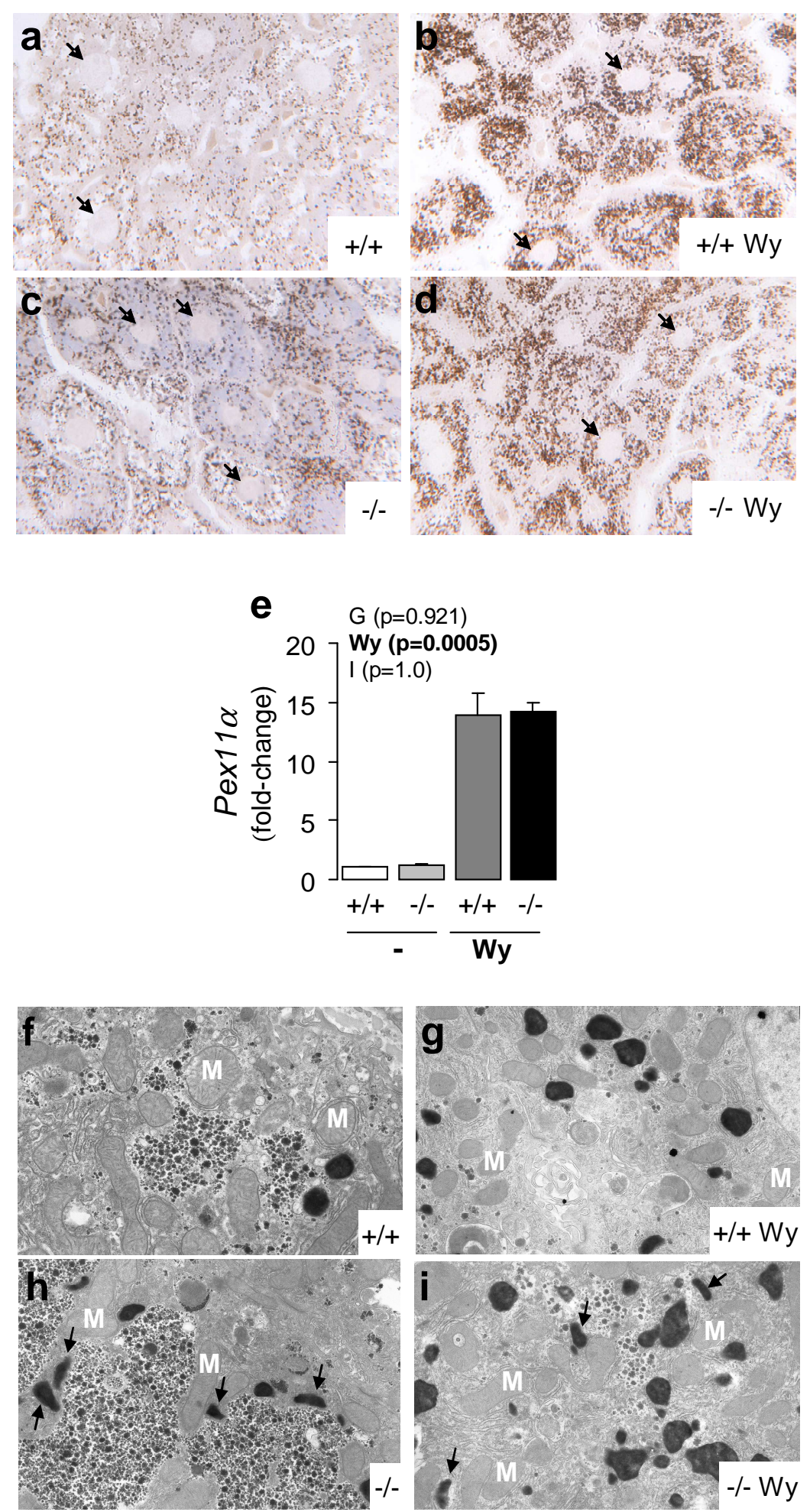

Fidaleo et al., Figure 4 
Fidaleo et al., ThB and genes of cholesterol biosynthesis in liver

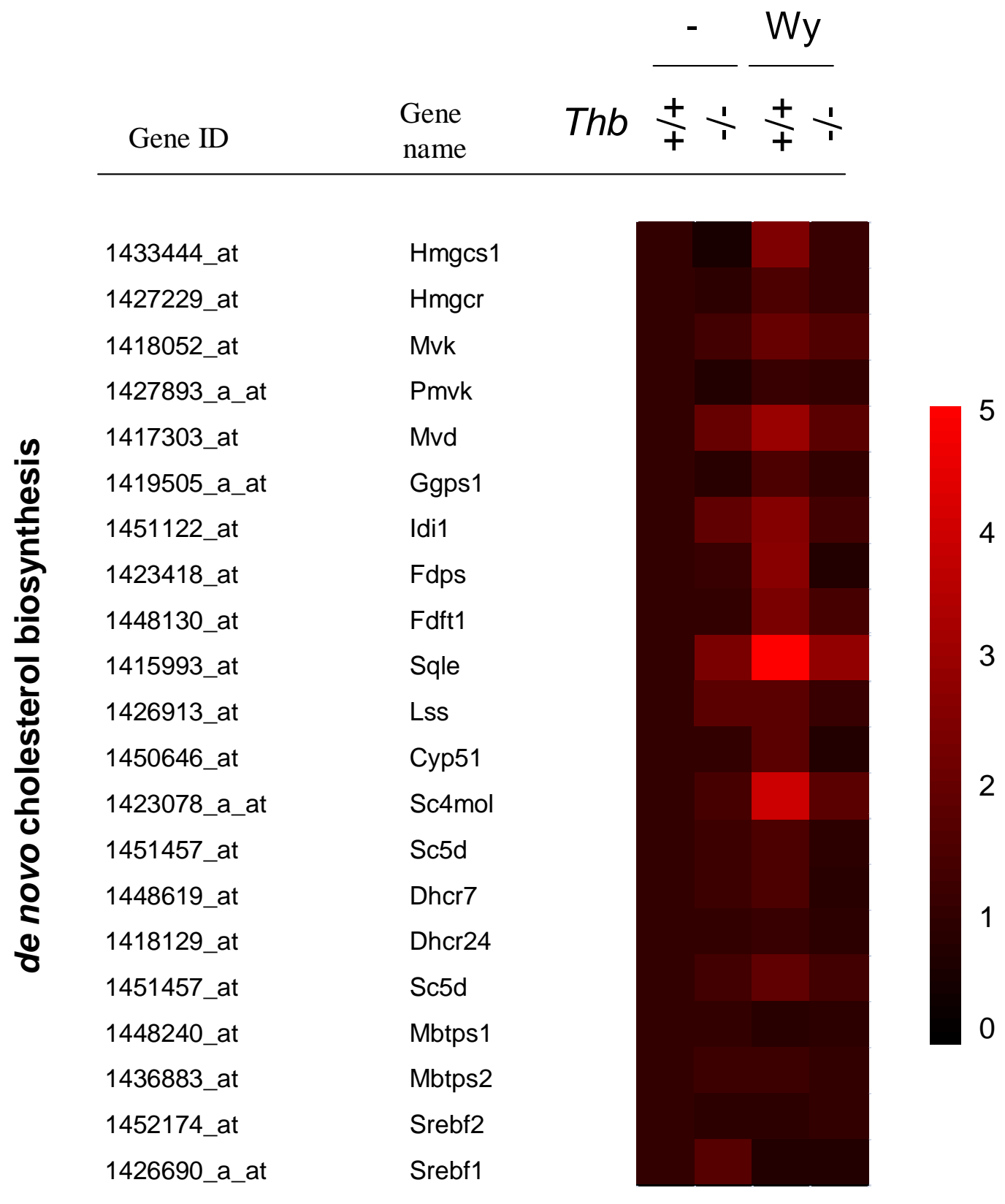

Fidaleo et al., Figure 5 
Fidaleo et al., ThB and genes of cholesterol biosynthesis in liver
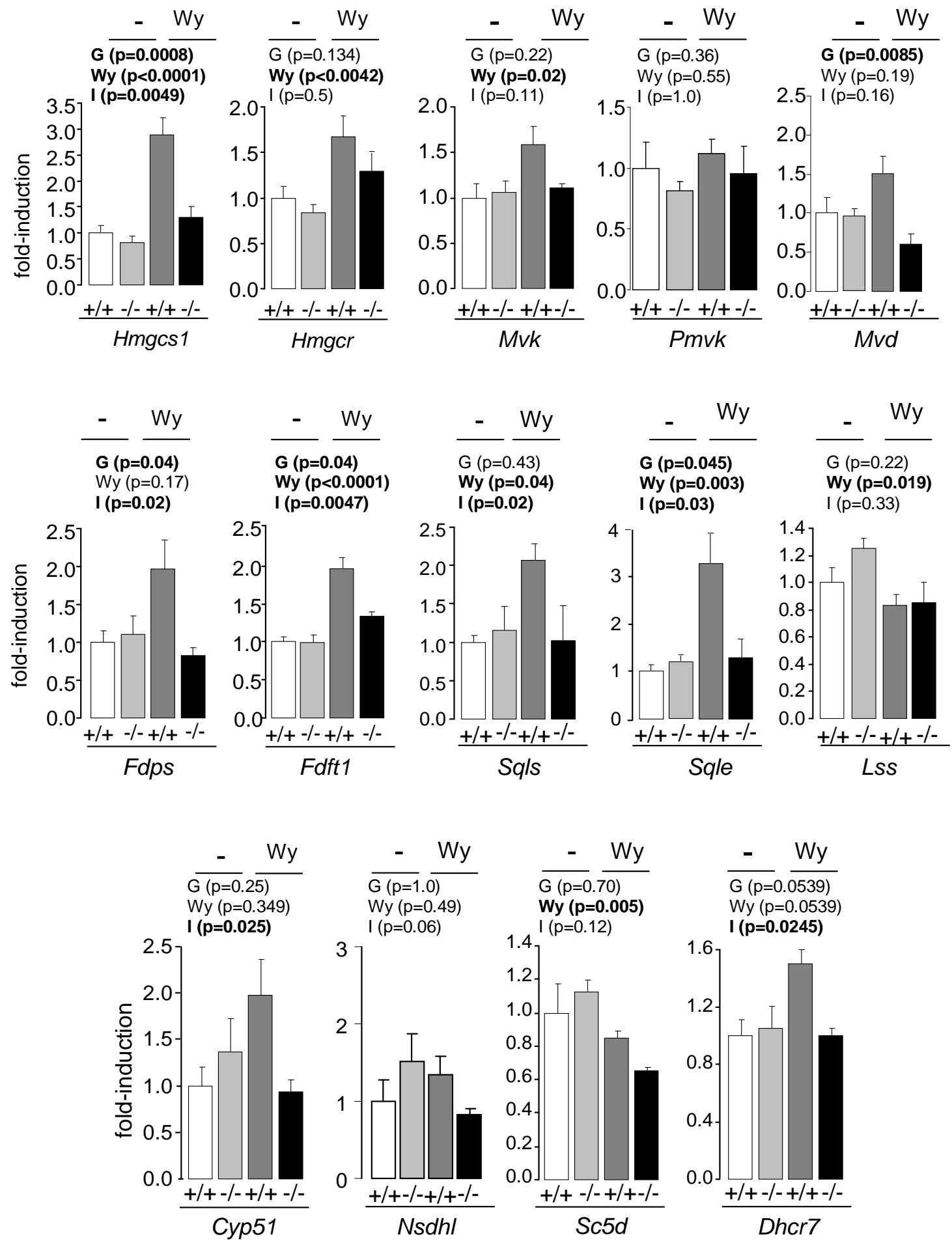

Fidaleo et al., Figure 6 
Fidaleo et al., ThB and genes of cholesterol biosynthesis in liver
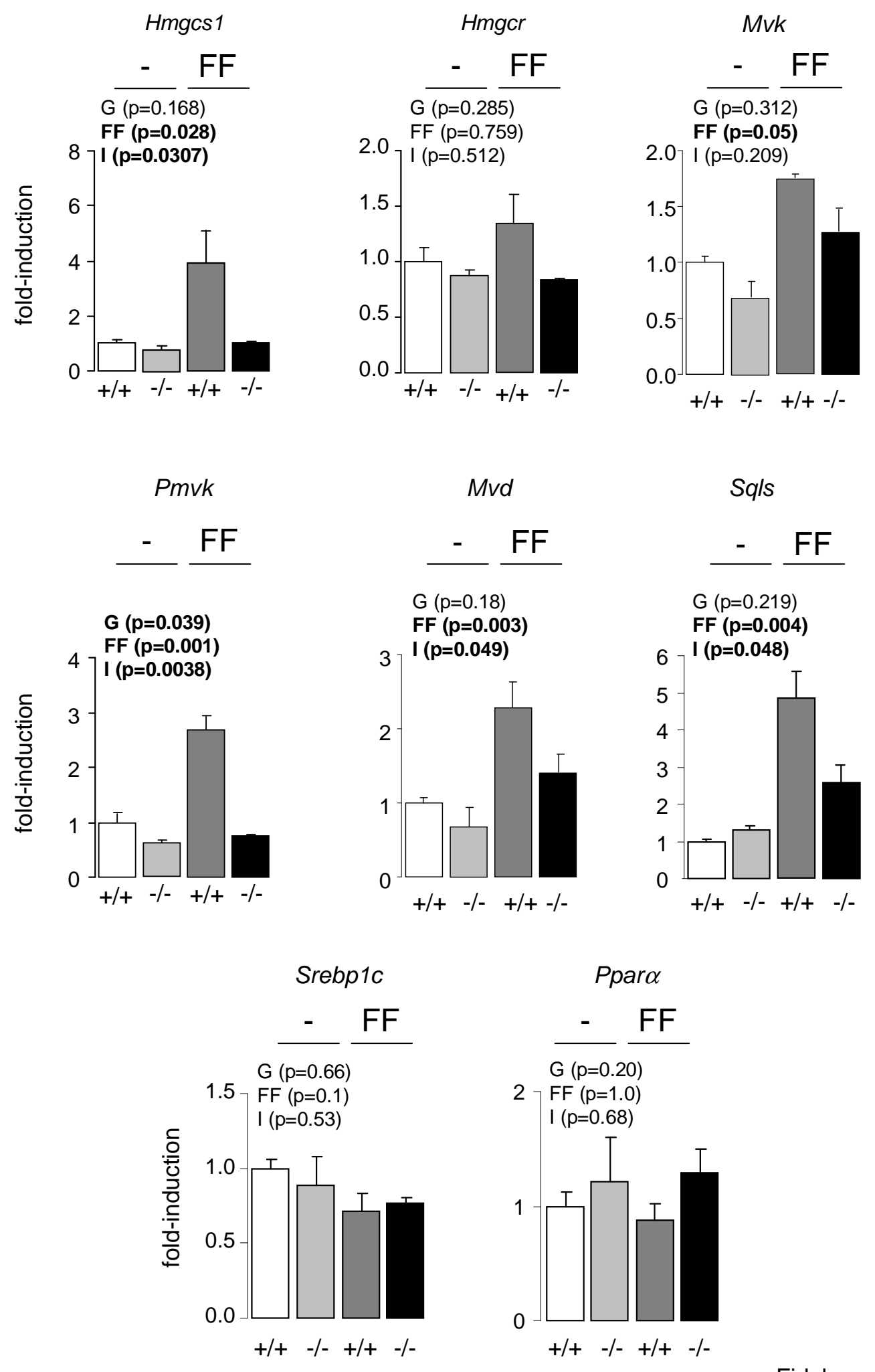

Fidaleo et al., Figure 7 
Fidaleo et al., ThB and genes of cholesterol biosynthesis in liver

a

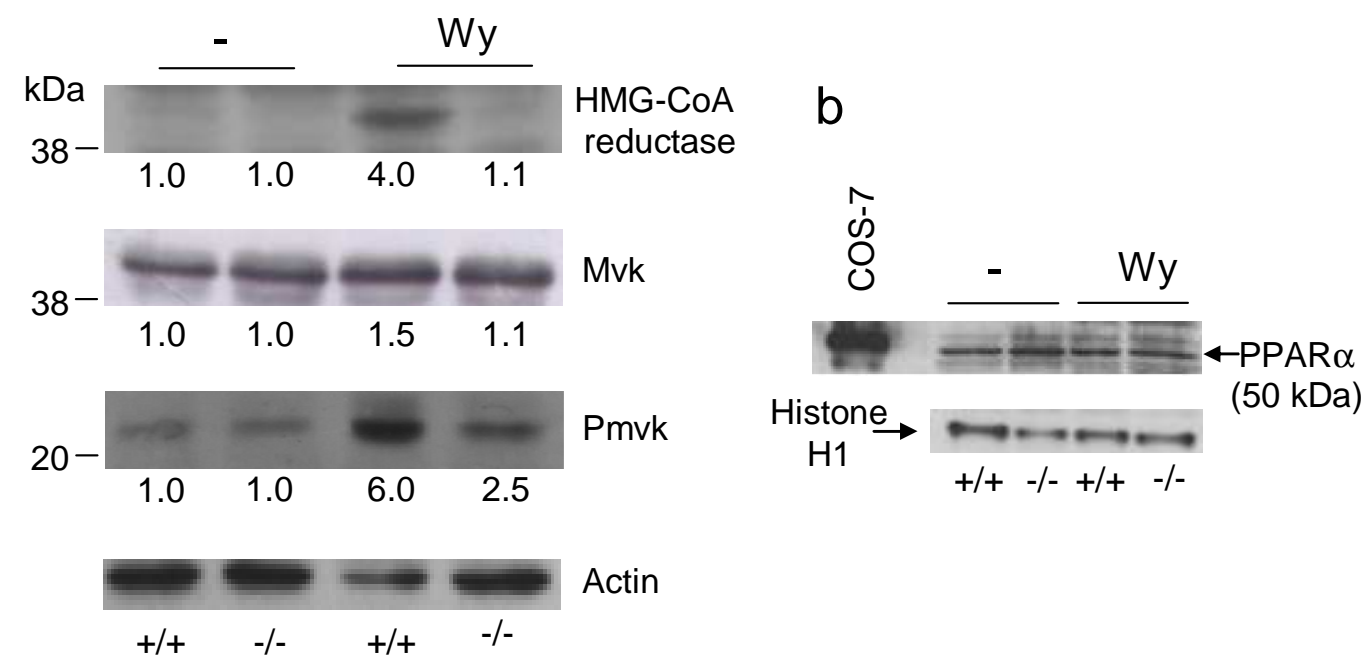

C
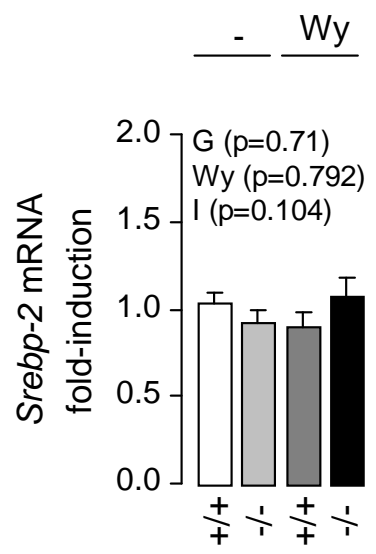

protein
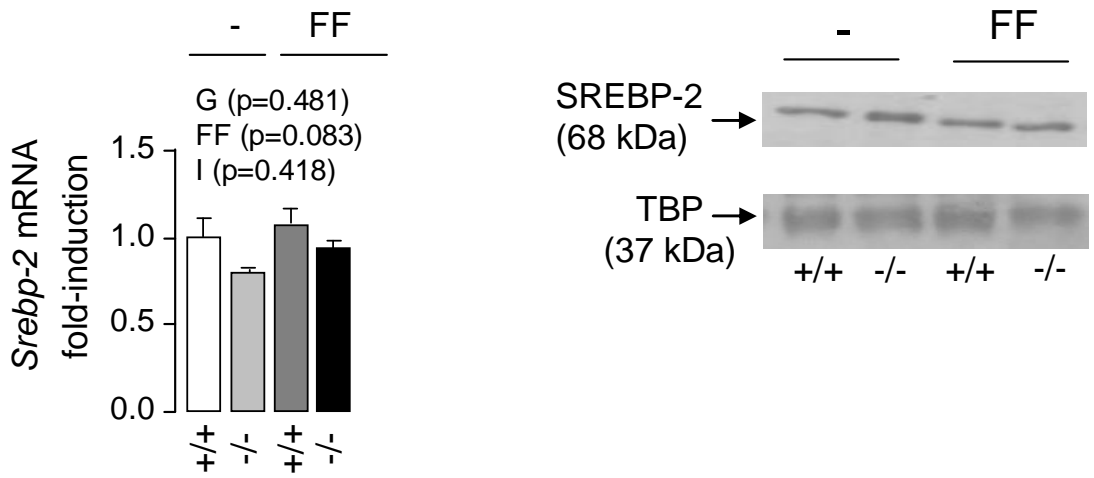

Fidaleo et al., Figure 8 
Fidaleo et al., ThB and genes of cholesterol biosynthesis in liver

A

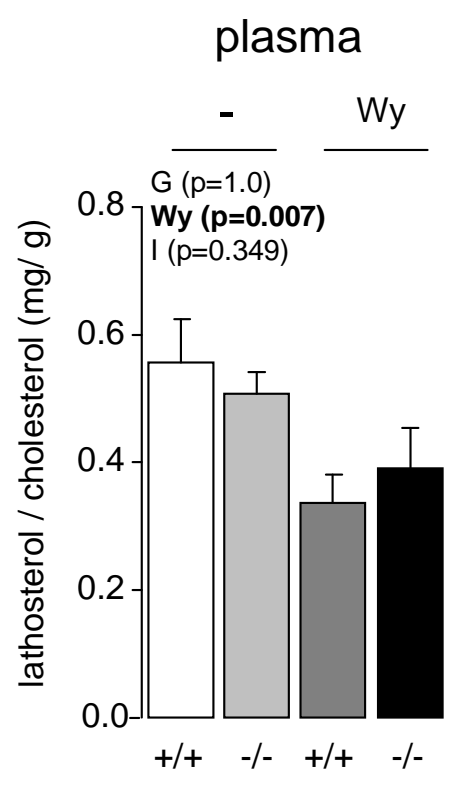

B

liver

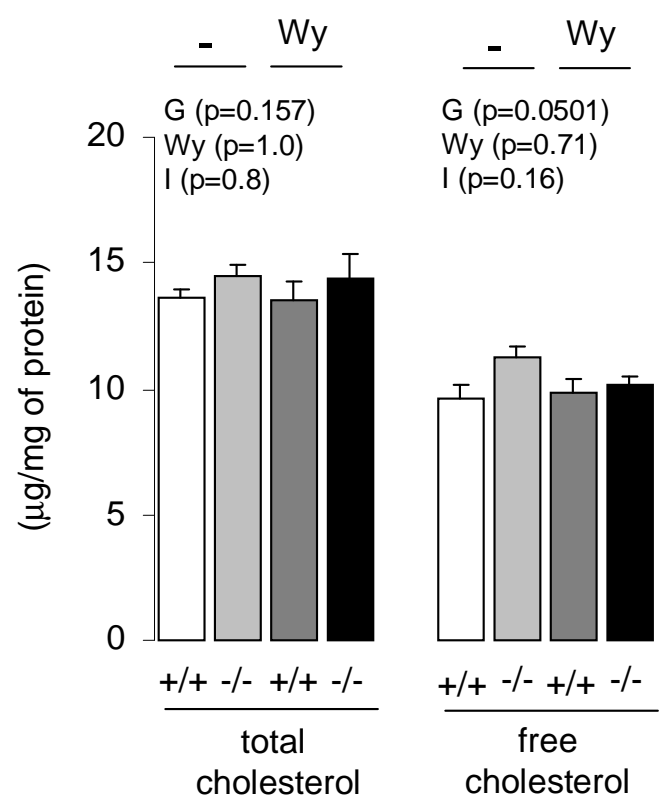

D

liver
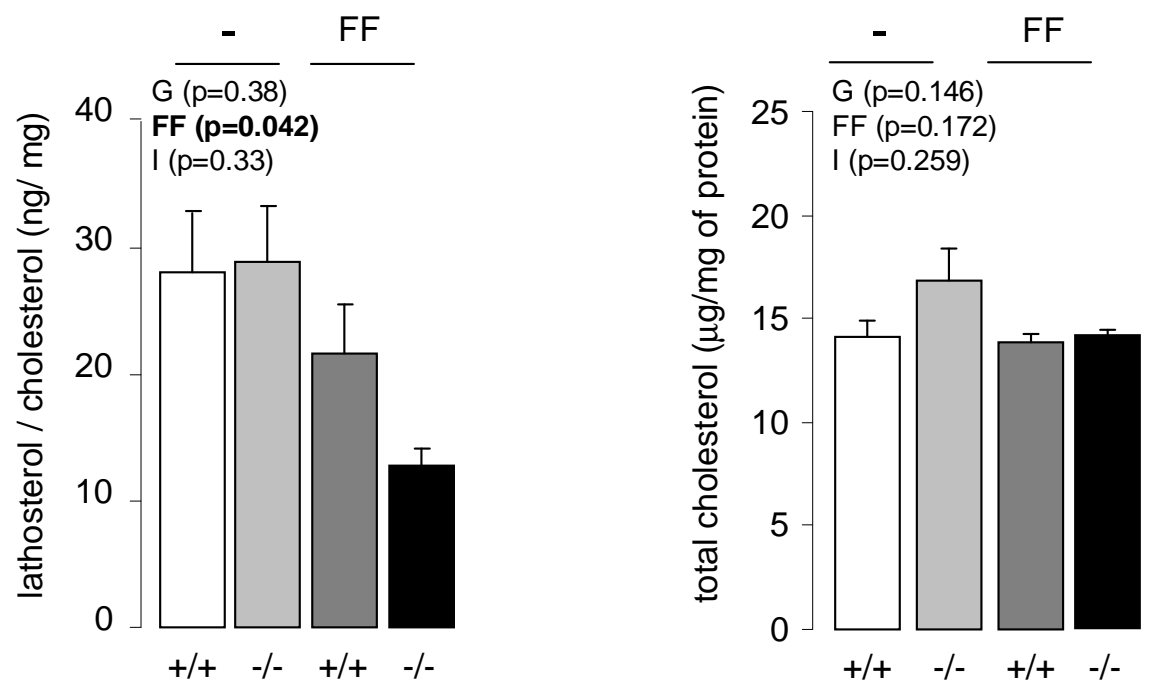

Fidaleo et al., Figure 9 
Fidaleo et al., ThB and genes of cholesterol biosynthesis in liver

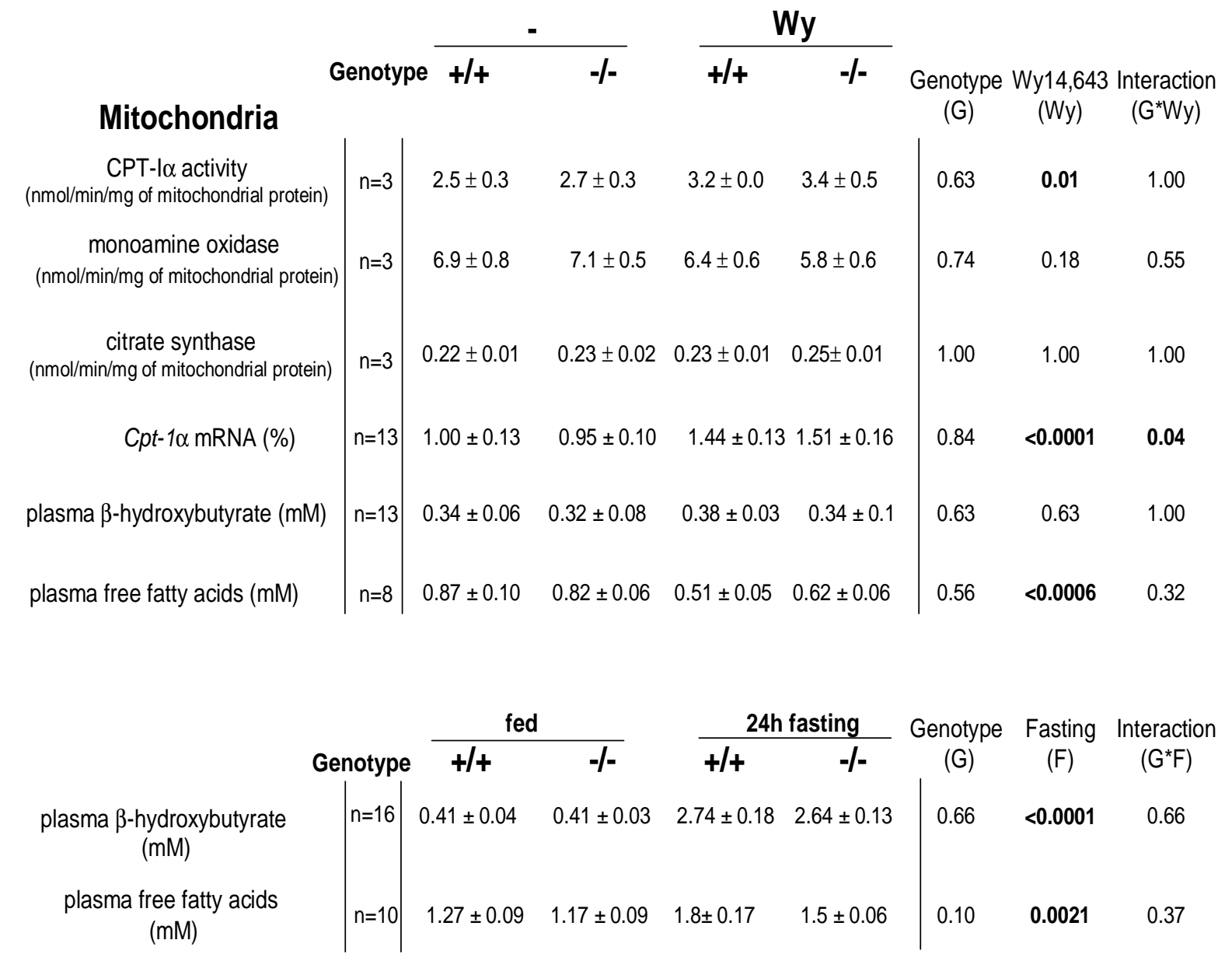

Fidaleo et al., Table 1 
Fidaleo et al., ThB and genes of cholesterol biosynthesis in liver

a
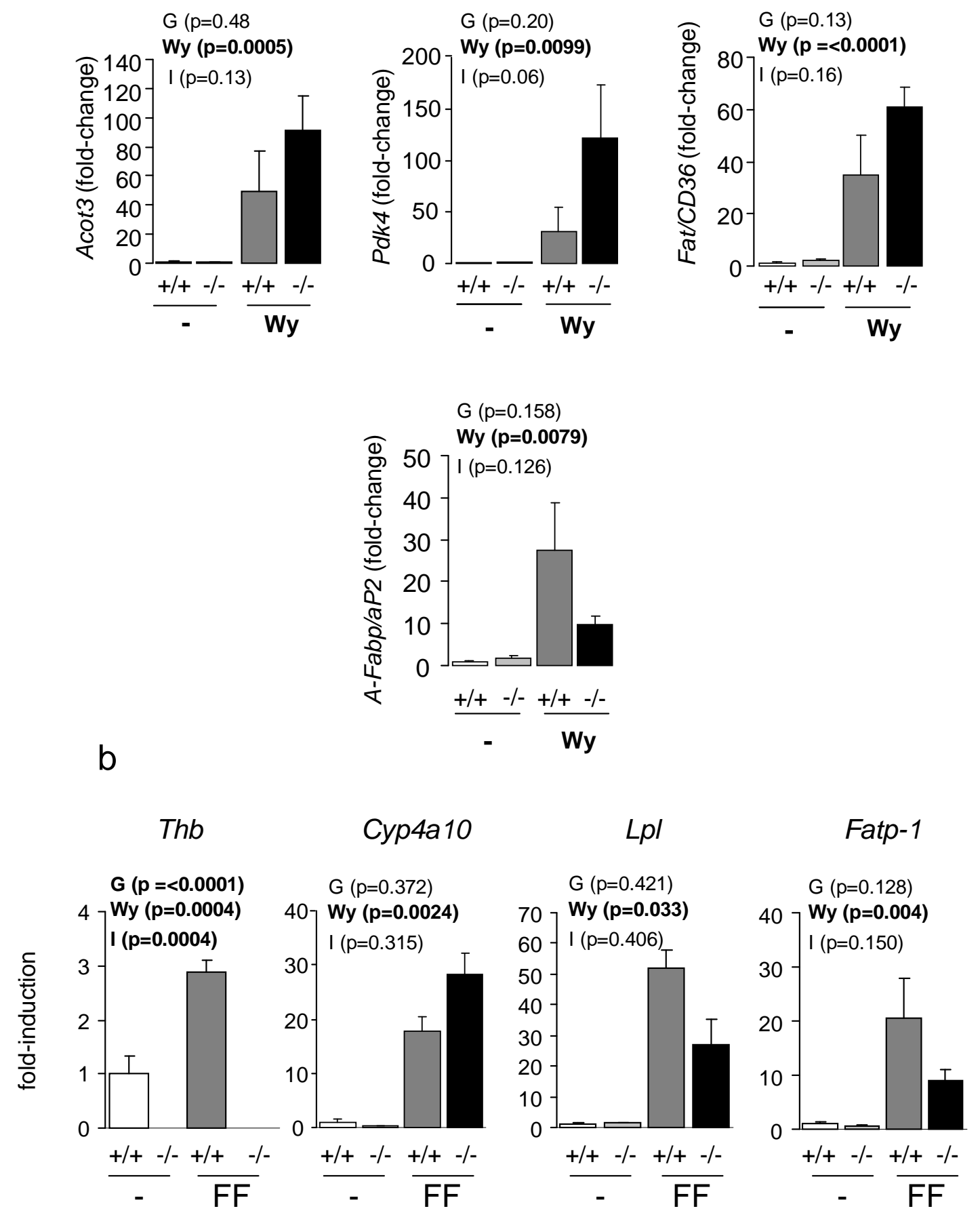
Fidaleo et al., ThB and genes of cholesterol biosynthesis in liver

\begin{tabular}{cccccc} 
A & B & C & D & E & F \\
& & \multicolumn{4}{c}{ fold-change } \\
Probe Set ID & Gene Symbol & WT & Ko & WT-Wy & KO-Wy \\
\cline { 2 - 6 } & & &
\end{tabular}

Peroxisome biogenesis

$\begin{array}{ccccccl}\text { 1428716_at } & \text { Pex1 } & 1.0 & 1.1 & 1.1 & 1.1 & \text { peroxisome biogenesis factor 1 } \\ \text { 1454044_a_at } & \text { Pex3 } & 1.0 & 1.1 & 1.5 & 1.4 & \text { peroxisomal biogenesis factor } 3 \\ \text { 1417442_a_at } & \text { Pex3 } & 1.0 & 1.0 & 1.7 & 1.5 & \text { peroxisomal biogenesis factor } 3 \\ \text { 1426770_at } & \text { Pex5 } & 1.0 & 1.1 & 1.4 & 1.2 & \text { peroxisome biogenesis factor } 5 \\ \text { 1422063_a_at } & \text { Pex5 } & 1.0 & 1.1 & 1.1 & 1.2 & \text { peroxisome biogenesis factor } 5 \\ \text { 1424078_s_at } & \text { Pex6 } & 1.0 & 0.7 & 0.7 & 0.8 & \text { peroxisomal biogenesis factor 6 } \\ \text { 1454738_x_at } & \text { Pex6 } & 1.0 & 1.1 & 1.0 & 0.9 & \text { peroxisomal biogenesis factor 6 } \\ \text { 1451226_at } & \text { Pex6 } & 1.0 & 1.0 & 0.9 & 1.1 & \text { peroxisomal biogenesis factor 6 } \\ \text { 1418988_at } & \text { Pex7 } & 1.0 & 1.0 & 1.1 & 1.1 & \text { peroxisome biogenesis factor 7 } \\ \text { 1456646_at } & \text { Pex10 } & 1.0 & 1.0 & 1.2 & 1.1 & \text { peroxisome biogenesis factor 10 } \\ \text { 1449442_at } & \text { Pex11a } & 1.0 & 0.7 & 1.7 & 2.1 & \text { peroxisomal biogenesis factor 11a } \\ \text { 1419365_at } & \text { Pex11a } & 1.0 & 0.7 & 1.4 & 1.8 & \text { peroxisomal biogenesis factor 11a } \\ \text { 1420460_a_at } & \text { Pex11b } & 1.0 & 1.0 & 1.3 & 1.1 & \text { peroxisomal biogenesis factor 11b } \\ \text { 1451213_at } & \text { Pex11b } & 1.0 & 0.9 & 0.9 & 0.9 & \text { peroxisomal biogenesis factor 11b } \\ \text { 1429407_at } & \text { Pex11c } & 1.0 & 0.7 & 1.1 & 0.9 & \text { peroxisomal biogenesis factor 11c } \\ \text { 1430856_at } & \text { Pex11c } & 1.0 & 1.5 & 1.2 & 1.2 & \text { peroxisomal biogenesis factor 11c } \\ \text { 1430857_s_at } & \text { Pex11c } & 1.0 & 0.8 & 1.1 & 1.1 & \text { peroxisomal biogenesis factor 11c } \\ \text { 1416259_at } & \text { Pex12 } & 1.0 & 0.9 & 0.9 & 0.9 & \text { peroxisomal biogenesis factor 12 } \\ \text { 1422471_at } & \text { Pex13 } & 1.0 & 1.1 & 1.0 & 1.2 & \text { peroxisomal biogenesis factor 13 } \\ \text { 1419053_at } & \text { Pex14 } & 1.0 & 0.9 & 1.1 & 1.2 & \text { peroxisomal biogenesis factor 14 } \\ \text { 1425021_a_at } & \text { Pex16 } & 1.0 & 0.8 & 1.6 & 1.6 & \text { peroxisome biogenesis factor 16 } \\ \text { 1455208_at } & \text { Pex19 } & 1.0 & 0.7 & 1.4 & 0.6 & \text { peroxisome biogenesis factor 19 }\end{array}$

Peroxisomal $\beta$-oxidation

\begin{tabular}{cccccll}
\hline 1416947_s_at & Acaa1 & 1.0 & 0.2 & 2.9 & 0.6 & thiolase a \& b \\
1416946_a_at & Acaa1 & 1.0 & 0.2 & 3.8 & 0.7 & thiolase a \& b \\
1456011_x_at & Acaa1 & 1.0 & 1.4 & 2.6 & 2.4 & thiolase a \\
1424451_at & Acaa1 & 1.0 & 0.0 & 2.1 & 0.0 & thiolase b \\
1416409_at & Acox1 & 1.0 & 1.0 & 2.9 & 3.3 & acyl-CoA-oxidase 1 \\
1416408_at & Acox1 & 1.0 & 0.9 & 2.1 & 2.2 & acyl-CoA-oxidase 1 \\
1448382_at & MFP-1 / L-PBE / Ehhadh & 1.0 & 0.7 & 5.2 & 5.6 & MFP-1 / L-PBE/Ehhadh \\
1455777_x_at & Hsd17b4/MFP-2 & 1.0 & 0.9 & 1.5 & 1.6 & Hsd17b4, hydroxysteroid (17-beta) dehydrogenase 4 \\
1417369_at & Hsd17b4/MFP-2 & 1.0 & 0.9 & 1.6 & 1.6 & Hsd17b4, hydroxysteroid (17-beta) dehydrogenase 4 \\
1448491_at & Ech1 & 1.0 & 0.7 & 2.3 & 2.6 & Ech1, enoyl-COA hydratase 1 \\
1449686_s_at & Scp2 & 1.0 & 0.9 & 0.9 & 1.0 & sterol carrier protein-2 \\
1419974_at & Scp2 & 1.0 & 2.1 & 1.5 & 4.4 & sterol carrier protein-2 \\
1426219_at & Scp2 & 1.0 & 1.1 & 1.1 & 1.2 & sterol carrier protein-2 \\
1420673_a_at & Acox2 & 1.0 & 1.1 & 1.2 & 1.4 & acyl-Coenzyme A oxidase 2, branched chain \\
1422604_at & Uox & 1.0 & 1.1 & 1.0 & 1.0 & urate oxidase \\
1416679_at & Abcd3 & 1.0 & 0.9 & 1.5 & 1.6 & PMP70/ABCD3 \\
1416430_at & Cat & 1.0 & 0.9 & 0.9 & 0.9 & catalase \\
1416429_a_at & Cat & 1.0 & 1.0 & 0.9 & 0.9 & catalase \\
1422925_s_at & Acot3 & 1.0 & 1.0 & 7.8 & 7.3 & acyl-CoA thioesterase 3 \\
1417449_at & Acot8 & 1.0 & 0.6 & 2.0 & 1.9 & acyl-CoA thioesterase 8
\end{tabular}

Fidaleo et al., Supplemental Table 1 
Fidaleo et al., ThB and genes of cholesterol biosynthesis in liver

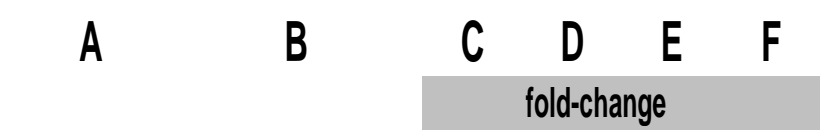

Probe Set ID Gene Symbol WT $\quad$ KO WT-Wy KO-Wy

\section{Mitochondrial $\beta$-oxidation and markers}

\begin{tabular}{lllllll}
\hline 1438156_x_at & Cpt1a & 1.0 & 0.9 & 1.2 & 1.6 & carnitine palmitoyltransferase 1a, liver \\
1434866_x_at & Cpt1a & 1.0 & 0.9 & 1.2 & 1.6 & carnitine palmitoyltransferase 1a, liver \\
1460409_at & Cpt1a & 1.0 & 0.9 & 1.6 & 2.0 & carnitine palmitoyltransferase 1a, liver \\
1418321_at & Cpt2 & 1.0 & 0.8 & 2.4 & 2.5 & carnitine palmitoyltransferase 2 \\
1419367_at & Decr1 & 1.0 & 0.8 & 2.4 & 2.8 & 2,4 -dienoyl CoA reductase 1, mitochondrial \\
1449443_at & Decr1 & 1.0 & 0.8 & 1.6 & 2.2 & 2,4 -dienoyl CoA reductase 1, mitochondrial \\
1452173_at & Hadha & 1.0 & 0.9 & 1.9 & 2.1 & hydroxyacyl-Coenzyme A dehydrogenase/3-ketoacyl-Coenzyme A thiolase/enoyl-Coen \\
1426522_at & Hadhb & 1.0 & 0.8 & 2.1 & 2.2 & hydroxyacyl-Coenzyme A dehydrogenase/3-ketoacyl-Coenzyme A thiolase/enoyl-Coen \\
1460184_at & Hadhsc & 1.0 & 1.1 & 1.6 & 1.7 & L-3-hydroxyacyl-Coenzyme A dehydrogenase, short chain \\
1460216_at & Acads & 1.0 & 0.7 & 2.1 & 1.2 & acyl-Coenzyme A dehydrogenase, short chain \\
1448987_at & Acadl & 1.0 & 0.9 & 2.0 & 2.1 & acetyl-Coenzyme A dehydrogenase, long-chain \\
1424184_at & Acadvl & 1.0 & 1.0 & 1.4 & 1.7 & acyl-Coenzyme A dehydrogenase, very long chain \\
1423108_at & Slc25a20 & 1.0 & 0.8 & 1.7 & 1.8 & solute carrier family 25 (mitochondrial carnitine/acylcarnitine translocase), member 20 \\
1423109__at & Slc25a20 & 1.0 & 0.8 & 1.7 & 1.7 & solute carrier family 25 (mitochondrial carnitine/acylcarnitine translocase), member 20 \\
1424639_a_at & Hmgcl & 1.0 & 1.0 & 1.6 & 1.9 & 3-hydroxy-3-methylglutaryl-Coenzyme A lyase \\
1431833_a_at & Hmgcs2 & 1.0 & 0.9 & 1.1 & 1.4 & 3-hydroxy-3-methylglutaryl-Coenzyme A synthase 2 \\
1423858_a_at & Hmgcs2 & 1.0 & 0.7 & 1.3 & 1.3 & 3-hydroxy-3-methylglutaryl-Coenzyme A synthase 2 \\
1422578_at & Cs & 1.0 & 1.0 & 1.0 & 0.9 & citrate synthase \\
1450667_a_at & Cs & 1.0 & 1.0 & 0.9 & 0.9 & citrate synthase \\
1428667_at & Maoa & 1.0 & 1.4 & 1.6 & 1.7 & monoamine oxidase A \\
1434354_at & Maob & 1.0 & 1.2 & 1.1 & 1.1 & monoamine oxidase B
\end{tabular}

Microsomal oroxidation

\begin{tabular}{llllccl}
\hline 1423257_at & Cyp4a14 & 1.0 & 0.3 & 1.6 & 1.7 & cytochrome P450, family 4, subfamily a, polypeptide 14 \\
1424943_at & Cyp4a10 & 1.0 & 0.3 & 11.1 & 11.1 & cytochrome P450, family 4, subfamily a, polypeptide 10 \\
1415776_at & Aldh3a2 & 1.0 & 0.9 & 3.0 & 3.9 & aldehyde dehydrogenase family 3, subfamily A2
\end{tabular}

Cell cycle/cell proliferation

\begin{tabular}{|c|c|c|c|c|c|c|}
\hline 1448698_at & Ccdn1 & 1.0 & 1.1 & 0.6 & 0.8 & cyclin D1 \\
\hline 1417420_at & Ccdn1 & 1.0 & 1.0 & 0.6 & 0.8 & cyclin D1 \\
\hline 1416122_at & Ccdn2 & 1.0 & 1.2 & 0.7 & 0.9 & cyclin D2 \\
\hline 1448364_at & Ccdn2 & 1.0 & 1.0 & 0.7 & 0.7 & cyclin D2 \\
\hline 1416488_at & Cong2 & 1.0 & 0.7 & 1.4 & 1.6 & cyclin G2 \\
\hline 1448364_at & Ccng2 & 1.0 & 0.8 & 2.2 & 2.0 & cyclin G2 \\
\hline 1424001_at & Mki67ip & 1.0 & 1.1 & 1.1 & 1.3 & Mki67 (FHA domain) interacting nucleolar phosphoprotein \\
\hline 1427005_at & Plk2 & 1.0 & 0.8 & 0.7 & 0.5 & polo-like kinase 2 (Drosophila) \\
\hline 1434496_at & Plk3 & 1.0 & 0.5 & 1.4 & 2.1 & polo-like kinase 3 (Drosophila) \\
\hline 1416868_at & Cdkn2c & 1.0 & 1.2 & 1.5 & 1.2 & cyclin-dependent kinase inhibitor $2 \mathrm{C}$ \\
\hline 1437580_S_at & Nek2 & 1.0 & 1.2 & 1.6 & 1.7 & NIMA (never in mitosis gene a)- related expressed kinase 2 \\
\hline 1452040_a_at & Cdca3 & 1.0 & 1.3 & 2.2 & 1.9 & cell division cycle associated 3 \\
\hline 1452040_a_at & Tde2l & 1.0 & 0.7 & 26 & 12 & tumor differentially expressed 2-like \\
\hline \multicolumn{7}{|c|}{ Pro-apoptotic genes } \\
\hline 1450971_at & Gadd45b & 1.0 & 0.5 & 4.6 & 3.3 & growth arrest and DNA-damage- inducible 45 beta \\
\hline 1416837_at & Bax & 1.0 & 0.9 & 1.2 & 0.7 & Bcl2-associated X protein \\
\hline \multicolumn{7}{|c|}{ Anti-apoptotic genes } \\
\hline 1418528_at & Dad1 & 1.0 & 0.8 & 0.7 & 0.6 & defender against cell death 1 \\
\hline
\end{tabular}


Fidaleo et al., ThB and genes of cholesterol biosynthesis in liver

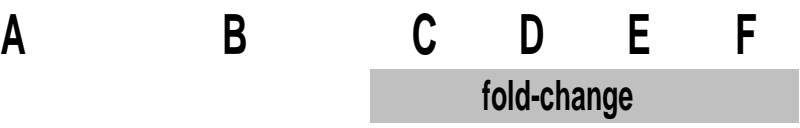

Probe Set ID Gene Symbol $\quad$ WT $\quad$ KO $\quad$ WT-Wy $\quad$ KO-Wy

De novo cholesterol biosynthesis

\begin{tabular}{|c|c|c|c|c|c|c|}
\hline 1433445 x_at & Hmgcs1 & 1.0 & 0.7 & 2.3 & 1.2 & 3-hydroxy-3-methylglutaryl-Coenzyme A synthase 1 \\
\hline 1433443_a_at & Hmgcs1 & 1.0 & 0.7 & 2.5 & 1.3 & 3-hydroxy-3-methylglutaryl-Coenzyme A synthase 1 \\
\hline 1433444_at & Hmgcs1 & 1.0 & 0.5 & 2.5 & 1.1 & 3-hydroxy-3-methylglutaryl-Coenzyme A synthase 1 \\
\hline 1433446_at & Hmgcs1 & 1.0 & 0.6 & 2.0 & 1.1 & 3-hydroxy-3-methylglutaryl-Coenzyme A synthase 1 \\
\hline 1427229_at & Hmgcr & 1.0 & 0.9 & 1.5 & 1.1 & 3-hydroxy-3-methylglutaryl-Coenzyme A reductase \\
\hline 1418052_at & Mvk & 1.0 & 1.3 & 2.0 & 1.6 & mevalonate kinase \\
\hline 1427893_a_at & Pmvk & 1.0 & 0.7 & 1.1 & 1.0 & phosphomevalonate kinase \\
\hline 1448663_s_at & Mvd & 1.0 & 1.3 & 2.5 & 0.6 & mevalonate (diphospho) decarboxylase \\
\hline 1417303_at & Mvd & 1.0 & 2.0 & 3.0 & 1.8 & mevalonate (diphospho) decarboxylase \\
\hline 1419805_s_at & Ggps1 & 1.0 & 0.9 & 1.0 & 0.9 & geranylgeranyl diphosphate synthase 1 \\
\hline 1419505_a_at & Ggps1 & 1.0 & 0.8 & 1.5 & 1.0 & geranylgeranyl diphosphate synthase 1 \\
\hline 1451122_at & Idi1 & 1.0 & 1.9 & 2.6 & 1.3 & isopentenyl-diphosphate delta isomerase \\
\hline 1423418 at & Fdps & 1.0 & 1.1 & 2.7 & 0.7 & farnesyl diphosphate synthetase \\
\hline 1438322_x_at & Fdft1 & 1.0 & 1.1 & 2.0 & 1.2 & farnesyl diphosphate farnesyl transferase 1 \\
\hline 1448130_at & Fdft1 & 1.0 & 1.0 & 2.4 & 1.4 & farnesyl diphosphate farnesyl transferase 1 \\
\hline 1415993_at & Sqle & 1.0 & 2.4 & 6.4 & 2.9 & squalene epoxidase \\
\hline 1420013_s_at & LSS & 1.0 & 1.6 & 2.3 & 1.5 & lanosterol synthase \\
\hline 1426913_at & Lss & 1.0 & 1.8 & 1.8 & 1.1 & lanosterol synthase \\
\hline 1450646_at & Cyp51 & 1.0 & 1.0 & 1.8 & 0.7 & cytochrome P450, family 51; lanosterol 14a-demethylase \\
\hline 1423078_a_at & Sc4mol & 1.0 & 1.4 & 4.0 & 1.8 & sterol-C4-methyl oxidase-like \\
\hline 1424709_at & Sc5d & 1.0 & 0.8 & 0.9 & 0.7 & sterol-C5-desaturase (fungal ERG3, delta-5-desaturase) homolog (S. cerevisae) \\
\hline 1434520 at & Sc5d & 1.0 & 1.1 & 0.7 & 0.6 & sterol-C5-desaturase (fungal ERG3, delta-5-desaturase) homolog (S. cerevisae) \\
\hline 1451457_at & Sc5d & 1.0 & 0.8 & 0.8 & 0.5 & sterol-C5-desaturase (fungal ERG3, delta-5-desaturase) homolog (S. cerevisae) \\
\hline 1448619_at & Dhcr7 & 1.0 & 1.0 & 1.1 & 0.9 & 7-dehydrocholesterol reductase \\
\hline 1451895_a_at & Dhcr24 & 1.0 & 1.1 & 1.7 & 1.6 & 24-dehydrocholesterol reductase / 3ß-hydroxysterol- $\Delta 24$ reductase (seladin-1) \\
\hline 1418130_at & Dhcr24 & 1.0 & 1.3 & 1.8 & 1.4 & 24-dehydrocholesterol reductase / $3 \beta$-hydroxysterol- $\Delta 24$ reductase (seladin-1) \\
\hline 1418129 at & Dhcr24 & 1.0 & 1.3 & 1.9 & 1.3 & 24-dehydrocholesterol reductase / 3ß-hydroxysterol- $\Delta 24$ reductase (seladin-1) \\
\hline 1416222_at & Nsdhl & 1.0 & 1.2 & 1.5 & 0.9 & $N A D(P)$ dependent steroid dehydrogenase-like \\
\hline 1448240_at & Mbtps1 & 1.0 & 1.0 & 0.8 & 0.9 & membrane-bound transcription factor peptidase, site 1 \\
\hline 1431385_a_at & Mbtps1 & 1.0 & 1.0 & 0.8 & 1.0 & membrane-bound transcription factor peptidase, site 1 \\
\hline 1436883_at & Mbtps2 & 1.0 & 1.2 & 1.2 & 1.0 & membrane-bound transcription factor peptidase, site 2 \\
\hline 1426690_a_at & Srebf1 & 1.0 & 1.7 & 0.7 & 0.7 & sterol regulatory element binding factor 1 \\
\hline 1452174_at & Srebf2 & 1.0 & 0.9 & 0.9 & 1.0 & sterol regulatory element binding factor 2 \\
\hline 1433520_at & Scap & 1.0 & 1.0 & 1.2 & 1.3 & SREBP cleavage activating protein \\
\hline 1454671_at & Insig1 & 1.0 & 1.3 & 1.1 & 0.8 & insulin induced gene 1 \\
\hline 1417980_a_at & Insig2 & 1.0 & 0.7 & 1.3 & 1.3 & insulin induced gene 2 \\
\hline 1417982_at & Insig2 & 1.0 & 0.8 & 1.1 & 1.2 & insulin induced gene 2 \\
\hline
\end{tabular}


Fidaleo et al., ThB and genes of cholesterol biosynthesis in liver

A B $\quad$ C $\underset{\text { fold-change }}{D} \quad$ F

Probe Set ID Gene Symbol $\quad$ WT $\quad$ KO $\quad$ WT-Wy $\quad$ KO-Wy

Sterol transport/trafficking

\begin{tabular}{cccccll}
\multicolumn{1}{l}{ Sterol transport/trafficking } & \\
\hline 1421840_at & Abca1 & 1.0 & 1.0 & 1.2 & 1.1 & ATP-binding cassette, sub-family A (ABC1), member 1 \\
1421839_at & Abca1 & 1.0 & 0.9 & 1.2 & 1.0 & ATP-binding cassette, sub-family A (ABC1), member 1 \\
1419393_at & Abcg5 & 1.0 & 1.5 & 1.2 & 1.5 & ATP-binding cassette, sub-family G (WHITE), member 5 \\
1420656_at & Abcg8 & 1.0 & 1.4 & 1.0 & 1.1 & ATP-binding cassette, sub-family G (WHITE), member 8 \\
1449817_at & Abcb11 & 1.0 & 1.2 & 0.4 & 0.5 & ATP-binding cassette, sub-family B (MDR/TAP), member 11 \\
1421821_at & Ldlr & 1.0 & 1.2 & 1.1 & 0.9 & low density lipoprotein receptor \\
1437453_s_at & Pcsk9 & 1.0 & 1.8 & 2.5 & 1.2 & proprotein convertase subtilisin/kexin type 9 \\
1423086_at & Npc1 & 1.0 & 1.1 & 1.1 & 0.9 & Niemann Pick type C1 \\
1448513_a_at & Npc2 & 1.0 & 1.0 & 0.8 & 0.7 & Niemann Pick type C2 \\
1416901_at & Npc2 & 1.0 & 1.0 & 1.0 & 0.8 & Niemann Pick type C2
\end{tabular}

Nuclear hormone receptors (towards lipid metabolism)

\begin{tabular}{ccccccc}
\hline 1449051_at & Nr1c1-Ppar $\alpha$ & 1.0 & 1.5 & 1.3 & 1.5 & peroxisome proliferator activated receptor alpha \\
1416353_at & Nr1h2-Lxr $\beta$ & 1.0 & 0.9 & 0.8 & 0.7 & nuclear receptor subfamily 1, group H, member 2 \\
1450444_a_at & Nr1h3-Lxra & 1.0 & 0.8 & 0.8 & 0.9 & nuclear receptor subfamily 1, group H, member 3 \\
1419105_at & Nr1h4-Fxra & 1.0 & 0.8 & 0.8 & 0.8 & nuclear receptor subfamily 1, group H, member 4 \\
1449854_at & Nr0b2-Shp & 1.0 & 0.8 & 0.6 & 1.1 & nuclear receptor subfamily 0, group B, member 2 \\
1429382_at & Nr1i3-Car & 1.0 & 1.0 & 1.4 & 1.7 & nuclear receptor subfamily 1, group I, member 3 \\
1455614_at & Nr1i3-Car & 1.0 & 0.7 & 1.1 & 1.0 & nuclear receptor subfamily 1, group I, member 3
\end{tabular}

SREBP interacting protein

\begin{tabular}{ccccccl}
\hline 1449945_at & Ppargc1b & 1.0 & 1.2 & 0.9 & 1.0 & peroxisome proliferative activated receptor, gamma, coactivator 1 beta \\
1434633_at & Crebbp & 1.0 & 0.9 & 1.0 & 0.8 & CREB binding protein \\
1420410_at & Nr5a2-Lrh1 & 1.0 & 2.4 & 1.4 & 1.6 & nuclear receptor subfamily 5, group A, member 2 \\
1449706_S_at & Nr5a2-Lrh1 & 1.0 & 1.4 & 1.1 & 1.3 & nuclear receptor subfamily 5, group A, member 2 \\
1456021_at & Atf6 & 1.0 & 0.7 & 1.0 & 1.0 & activating transcription factor 6 \\
1435444_at & Att6 & 1.0 & 0.8 & 0.7 & 0.6 & activating transcription factor 6 \\
1450447_at & $\mathrm{Nr} 2 a 1-H n f 4 \alpha$ & 1.0 & 1.3 & 1.4 & 1.7 & nuclear receptor subfamily 2, group A, member 1 \\
1427001_s_at & $\mathrm{Nr2a1-Hnf4 \alpha}$ & 1.0 & 1.0 & 0.9 & 1.1 & nuclear receptor subfamily 2, group A, member 1 \\
1421983_S_at & $\mathrm{Nr2a1-Hnf4 \alpha}$ & 1.0 & 1.1 & 0.9 & 1.1 & nuclear receptor subfamily 2, group A, member 1 \\
1427000_at & $\mathrm{Nr2a1-Hnf4 \alpha}$ & 1.0 & 0.9 & 1.0 & 1.0 & nuclear receptor subfamily 2, group A, member 1
\end{tabular}

Protein modification of SREBP

$\begin{array}{ccccccl}\text { 1454958_at } & \text { Gsk3b } & 1.0 & 1.1 & 1.0 & 1.0 & \text { glycogen synthase kinase 3 beta } \\ \text { 1439949_at } & \text { Gsk3b } & 1.0 & 1.0 & 1.0 & 1.0 & \text { glycogen synthase kinase 3 beta } \\ \text { 1448174_at } & \text { Cul1 } & 1.0 & 0.9 & 0.9 & 0.8 & \text { cullin 1 } \\ \text { 1416577_a_at } & \text { Rbx1 } & 1.0 & 0.9 & 0.8 & 0.9 & \text { ring-box 1 } \\ \text { 1448387_at } & \text { Rbx1 } & 1.0 & 1.1 & 0.9 & 1.0 & \text { ring-box 1 }\end{array}$

Miscellaneous (towards PPARalpha regulated genes)

\begin{tabular}{lllllll}
\hline 1423166_at & Cd36 & 1.0 & 0.9 & 9.6 & 10.3 & CD36 antigen \\
1450883_a_at & Cd36 & 1.0 & 0.9 & 9.5 & 9.0 & CD36 antigen \\
1450884_at & Cd36 & 1.0 & 0.8 & 6.9 & 6.6 & CD36 antigen \\
1417023_a_at & Fabp4 & 1.0 & 1.3 & 25.4 & 10.0 & fatty acid binding protein 4, adipocyte \\
1415904_at & Lpl & 1.0 & 1.9 & 5.6 & 6.0 & lipoprotein lipase \\
1431056_a_at & Lpl & 1.0 & 2.2 & 5.9 & 4.7 & lipoprotein lipase \\
1456424_s_at & Pltp & 1.0 & 1.0 & 3.6 & 3.0 & phospholipid transfer protein \\
1417963_at & Pltp & 1.0 & 0.7 & 4.0 & 3.5 & phospholipid transfer protein \\
1417273_at & Pdk4 & 1.0 & 0.7 & 7.0 & 4.0 & pyruvate dehydrogenase kinase, isoenzyme 4 \\
1422076_at & Acot4 & 1.0 & 1.0 & 2.9 & 3.7 & acyl-CoA thioesterase 4 \\
1422997_s_at & Acot1 //I Acot2 & 1.0 & 0.5 & 11.4 & 13.2 & acyl-CoA thioesterase 1/// acyl-CoA thioesterase 2 \\
1439478_at & Acot2 & 1.0 & 0.6 & 2.6 & 2.4 & acyl-CoA thioesterase 2
\end{tabular}


Fidaleo et al., ThB and genes of cholesterol biosynthesis in liver

\begin{tabular}{ccc}
\hline Gene & forward primer & reverse primer \\
\hline Thb & ATCCGGTTCTCTCGGTCGA & TGTGGTCAAGCATAGCATGCA \\
Tha & CCTGAACAGTGCTGAAGTGAG & ACAGTACACATTTACTGCATCCC \\
Scpx/Scp2 & AAGCCATTGCCAAGGTACGGAAG & GCCTGGACTGAACGGACACAAG \\
Acox-l & GTCTCGTCGTCAGGGCTTAG & TTGACCACACCCAATTAGCA \\
Acot3 & GCCCAACTGTGACTTCCATT & GGCATGTAACCCGTAGCACT \\
Pdk4 & TCCAACATCGGCGGAAACTTA & ACGGGAATCAAGCTCTTCTGG \\
Fat/Cd36 & CCGCTTAGTGAACACTCCTTC & TCTACAAACTCTGACAGGGCTTT \\
Cpt1 $\alpha$ & ATGGGCTGTGATCGGAACTG & GTCTTCCCAATAAGCATGTCTCC \\
Cdk1 & CTCAGTGGGAGCGACTCTTCA & GGCCTCTGTGGTACACGACAA \\
Cdk4 & ATGATCCTGCCAACGAATC & TCCATCCAGAGGCTACATC \\
Cdk1a/p21 & TGCCAGAGATGGAGGAGTCT & TTGTGCAGGTAGGAGTGCTG \\
Pcna & GCTCACAGGACACTGAGCAA & GCTTGACACCCACGGTATT \\
Pex11alpha & TTGGAATCCCAGAACAGGAG & GTGGCTAAGGTCTCGGCATA \\
HMG-CoA synthase & ACTGGCCGTAAATGGTTCAGA & CGGTTGAGGTTGGCTAATGTC \\
HMG-CoA reductase & GTGGCACCGGATGTCTTTG & ACTCTGACCAGATACCACGTT \\
Phosphomevalonate kinase & AGCTTGCCCGAATTGTATGTG & TCTGTTGTGAACCATGTGACTTC \\
Farnesyl diphosphate synthase & CATTGAGACCACGGAGATG & CATCTGGCAGAACCACTGTT \\
Farnesyl diphosphate farnesyl transferase-1 & GGAGGTCCTAGAGTACAATGCC & AAGCCTGGAGCAGTTCTACAC \\
Squalene synthase & TCCCACTGCTGTGTAACTTCC & TGTCTACAAATTCTGCCATCCC \\
Squalene epoxidase & TCCCACTGCTGTGTAACTTCC & TGTCTACAAATTCTGCCATCCC \\
Lanosterol synthase & ATAAGAAATGCGGGGATGTCAC & ATATCCGAGAGGCAGCGAC \\
Lanosterol-14alpha demethylase (CYP51) & CAGCAGTGAGAGACCTGGAA & AGAAGCGTTGATGTGACTGG \\
Steroid 5-alpha reductase 1 & CTGAGAGCTCTCGTGCTGT & TTCAAATGCCATTCGGTCT \\
7-alpha dehydrocholesterol reductase & TGAGTGTCATGCTGAGGGAT & TGTCGGACAATTAACCAAGC \\
Srebp-2 & ACCTAGCAGCTCATCCACCT & CTAAGGCCACTGACTGGTGA \\
36b4 & CTGCAGCCTCAAGTGCAAAG & CAGTGGCCATTGGCTGTCT \\
& ATGGGTACAAGCGCGTCCTG & GCCTTGACCTTTTCAGTAAG \\
\hline
\end{tabular}

Fidaleo et al. , Supplemental Table 2 